\title{
Article \\ A Thermodynamic Analysis of Naphtha Catalytic Reforming Reactions to Produce High-Octane Gasoline
}

\author{
Jeremías Martínez *, María Antonieta Zúñiga-Hinojosa and Richard Steve Ruiz-Martínez *
}

Citation: Martínez, J.; ZúñigaHinojosa, M.A.; Ruiz-Martínez, R.S A Thermodynamic Analysis of Naphtha Catalytic Reforming Reactions to Produce High-Octane Gasoline. Processes 2022, 10, 313. https://doi.org/10.3390/pr10020313

Academic Editor: Alessandro D' Adamo

Received: 10 January 2022 Accepted: 4 February 2022 Published: 6 February 2022

Publisher's Note: MDPI stays neutral with regard to jurisdictional claims in published maps and institutional affiliations.

Copyright: (C) 2022 by the authors. Licensee MDPI, Basel, Switzerland. This article is an open access article distributed under the terms and conditions of the Creative Commons Attribution (CC BY) license (https:// creativecommons.org/licenses/by/ $4.0 /)$
Unidad Iztapalapa, División de Ciencias Básicas e Ingeniería, Departamento de Ingeniería de Procesos e Hidráulica, Universidad Autónoma Metropolitana, Av. San Rafael Atlixco 186, Leyes de Reforma 1ra Secc. Iztapalapa, Ciudad de Mexico 09340, Mexico; mzunigahinojosa@yahoo.com.mx

* Correspondence: jmsalced@outlook.com (J.M.); rmr@xanum.uam.mx (R.S.R.-M.)

\begin{abstract}
The catalytic naphtha reforming process is key to producing high-octane gasoline. Dozens of components are involved in this process in hundreds of individual catalytic reactions. Calculations of concentrations at equilibrium, using equilibrium constants, are commonly performed for a small number of simultaneous reactions. However, the Gibbs free energy minimization method is recommended for the solution of complex reaction systems. This work aims to analyze, from the point of view of thermodynamic equilibrium, the effect of temperature, pressure, and the $\mathrm{H}_{2} / \mathrm{HC}$ ratio on the reactions of the catalytic reformation process and evaluate their impact on the production of high-octane gasoline. Gibbs's free energy minimization method was used to evaluate the molar concentrations at equilibrium. The results were compared with those obtained in the simulation of a catalytic reforming process to evaluate the optimal conditions under which the process should operate.
\end{abstract}

Keywords: thermodynamic equilibrium; Gibbs free energy; catalytic reforming; Research Octane Number

\section{Introduction}

The maximum amounts of products formed from a specific reaction are achieved at equilibrium under specific pressure and temperature [1]. Therefore, knowing equilibrium compositions can help design new catalysts and processes and improve existing plant operations by maximizing the production of desired products and eliminating or reducing the undesired side reactions [1].

There are two general approaches for calculating chemical equilibrium compositions for multi-reaction systems based on the minimum free energy: the constant equilibrium method and the free energy minimization method. In the first method, the overall reactions are written, and their equilibrium constants are calculated. The mathematical expressions for the equilibrium reaction equations are usually non-linear, and their number and complexity increase as the number of species in a reaction increases. Some of the disadvantages of this method are complications for the appropriate component selection; numerical troubles with compositions that become extremely small; inconvenience in testing for the presence of some condensed species; difficulties in extending the generalized method to non-ideal equations of state [1-3].

Free energy minimization is a more direct and general method for solving complex chemical systems [4,5]. Gibbs's free energy minimization method does not consider individual equilibrium constants nor the chemistry of reactions; it is based on the principle that the total Gibbs free energy of the system has its minimum value at chemical equilibrium [4]. Gibbs's free energy minimization problems are typically based on equation solving methods and direct optimization strategies and are widely discussed elsewhere [2,3,6,7]. Equationsolving methods solve the non-linear equations obtained from the stationary conditions subjected to mass balance and chemical equilibrium constraints [8]. However, this method 
fails to converge to the correct solution when initial estimates are unsuitable, especially for non-ideal multicomponent and multi-reactive systems [6,8]. The use of Lagrange multipliers is usually the preferred approach for Gibbs minimization, but its performance is highly dependent on initial estimates of Lagrange multipliers [2,3,6,9]. Alternatively, stochastic optimization techniques have also been applied for minimizing the Gibbs free energy [3,6].

Gibbs's free energy minimization method has been used to study chemical systems of moderate complexity such as methanation reactions [4], steam reforming of methanol, ethanol, and glycerin for hydrogen production [10-12], reduction of silicon dioxide [13] and the esterification reaction [14]; and more complex systems such as the Claus process [1].

One of the objectives of this work is to apply Gibbs's free energy minimization method to the naphtha reforming process for calculating equilibrium compositions. Catalytic naphtha reforming is a key process to produce high-octane gasoline and aromatic feedstocks for petrochemical industries [15]. It is a multi-reactive system with more than 100 compounds participating in hundreds of individual catalytic reactions [16]. Since catalysts do not change the thermodynamics of a chemical reaction, we compared the equilibrium compositions with those obtained for a catalytic process.

The present work aims to thermodynamically analyze the effect of temperature, pressure, and $\mathrm{H}_{2} / \mathrm{HC}$ ratio on catalytic naphtha reforming. We compared the thermodynamic calculations with the simulated results obtained for a catalytic naphtha reforming plant. We analyzed the impact of the operating conditions on the Research Octane Number, one of the main parameters used in the quality control of gasoline.

To our knowledge, no thermodynamic analysis has been made for the catalytic naphtha reforming process based on Gibbs's free energy minimization method.

\section{Methodology}

\subsection{Problem Delimitation}

The naphtha feed to the catalytic reformer is a fraction of crude oil that boils between approximately 70 and $200{ }^{\circ} \mathrm{C}$. It is a very complex mixture consisting of about three hundred components with the carbon number range from 5 to $9+[17,18]$, mainly alkanes and cycloalkanes, although there may also be a small fraction of aromatics [19].

The naphtha reforming process aims to increase the low Research Octane Number $(\mathrm{RON})$. A Pt/Re bifunctional catalyst promotes the dehydrogenation and dehydroisomerization of naphthenes to aromatics, dehydrogenation of paraffins to olefins, dehydrocyclization of paraffins and olefins to aromatics, isomerization or hydroisomerization to iso-paraffins, isomerization of alkyl cyclopentanes and substituted aromatics and hydrocracking of paraffins and naphthenes to lower hydrocarbons $[18,19]$.

Many studies related to new catalyst development, kinetic and deactivation models, reactor configuration, and operation modes have been accomplished for the catalytic naphtha reforming process and are widely discussed in $[18,20]$.

A detailed reaction network, considering all components and reactions, is beyond the scope of this work. Subsequently, for the thermodynamics analysis, we grouped the components in gases, paraffins, naphthenes, and aromatics, and we assumed that they could be well represented for the model compounds given in Table 1. 
Table 1. Model compounds for the thermodynamics analysis.

\begin{tabular}{|c|c|c|c|}
\hline Symbol & Model Compound & Symbol & Model Compound \\
\hline \multicolumn{2}{|c|}{ Gases } & \multicolumn{2}{|c|}{ Isoparaffins } \\
\hline $\mathrm{H}_{2}$ & Hydrogen & $\mathrm{ip}_{6}$ & 2-Methylpentane \\
\hline $\mathrm{C}_{1}$ & Methane & $\mathrm{ip}_{7}$ & 2-Methylhexane \\
\hline $\mathrm{C}_{2}$ & Ethane & $\mathrm{ip}_{8}+$ & 2-Methylheptane \\
\hline $\mathrm{C}_{3}$ & Propane & \multicolumn{2}{|c|}{ Naphthenes } \\
\hline $\mathrm{C}_{4}$ & Butane & $\mathrm{N}_{6}$ & Methylcyclopentane \\
\hline $\mathrm{C}_{5}$ & Pentane & $\mathrm{N}_{7}$ & Methylcyclohexane \\
\hline & & $\mathrm{N}_{8}+$ & Ethylcyclohexane \\
\hline \multicolumn{2}{|c|}{ Paraffins } & \multicolumn{2}{|c|}{ Aromatics } \\
\hline $\mathrm{np}_{6}$ & n-hexane & $\mathrm{A}_{6}$ & Benzene \\
\hline $\mathrm{np}_{7}$ & $n$-heptane & $A_{7}$ & Toluene \\
\hline $\mathrm{np}_{8}+$ & n-octane & $\mathrm{A}_{8}+$ & Ethylbenzene \\
\hline
\end{tabular}

\subsection{Thermodynamic Analysis}

According to Gibbs's free energy minimization method, the total Gibbs free energy of a reactive system reaches a minimum value at equilibrium [4,21]. Equilibrium calculations involve the global minimization of Gibbs free energy constrained by the material balances and chemical equilibrium restrictions.

The total Gibbs free energy of the system is given as follows [5]:

$$
n G\left(n_{i}, T, P\right)=\sum_{i=1}^{N} n_{i} \Delta G_{f i}^{0}+\sum_{i=1}^{N} n_{i} R T \ln P+\sum_{i=1}^{N} n_{i} R T \ln y_{i}+\sum_{i=1}^{N} n_{i} R T \ln \hat{\varnothing}_{i}
$$

The global optimization problem can be solved by finding the set of $n_{i}$ that minimizes $n G$ (Equation (1)) for specified $T$ and $P$. In a reactive system, molecular species are not conserved; nevertheless, the total number of atoms of each element remains constant [21]. Subsequently, the material balance constraints are formulated as follow:

$$
\sum_{i} n_{i} a_{i j}=b_{j}, \quad j=1, \ldots, K
$$

The subscript $j$ identifies a particular atom, and $K$ is the total number of the different elements present in the system. The $b_{j}$ parameter is the total number of atomic masses of the $k$ th element in the system, while the $a_{i j}$ parameter is the number of atoms of the $k$ th element present in each molecule of chemical species $i$.

When liquid and gas phases are both present in an equilibrium mixture of reacting species, a vapor/liquid equilibrium criterion must be satisfied along with Equations (1) and (2). In our particular case, it is assumed that reforming reactions occur only in the gas phase, since they are carried out at high temperatures $(>600 \mathrm{~K})$.

\subsection{Standard Gibbs-Energy Change of Reaction}

The Standard Gibbs-energy change for the reactions at equilibrium is calculated as follows [21]:

$$
\frac{\Delta G^{o}}{R T}=\frac{\Delta G_{0}^{o}-\Delta H_{0}^{o}}{R T_{0}}+\frac{\Delta H_{0}^{o}}{R T}+\frac{1}{T} \int_{T_{0}}^{T} \frac{\Delta C_{P}^{o}}{R} d T-\int_{T_{0}}^{T} \frac{\Delta C_{P}^{o}}{R} d T
$$

Calculation of the Fugacity Coefficients

The fugacity coefficients were calculated according to the Soave-Redlich-Kwong equation of state [22]:

$$
\ln \hat{\varnothing}_{i}=\frac{B_{i}}{B}(z-1)-\ln (z-B)+\frac{A}{B}\left[\frac{B_{i}}{B}-\frac{2}{a \alpha} \sum_{j}^{m} y_{j}(a \alpha)_{i j}\right] \ln \left(1+\frac{B}{z}\right)
$$


Binary interaction parameters $k_{i j}$ were taken as 0 for hydrocarbon pairs and hydrogen as given in [22].

The SRK equation of state gives the compressibility factor $z$ :

$$
f(z)=z^{3}-z^{2}+\left(A-B-B^{2}\right) z-A B=0
$$

The critical properties and ideal gas standard Gibbs free energy at standard conditions and constants for $C_{P}$ calculations are shown in Tables 2 and 3, respectively.

Table 2. Critical properties and ideal gas standard Gibbs free energy [21].

\begin{tabular}{cccccc}
\hline Compound & $\mathbf{w}$ & $\mathbf{T}_{\mathbf{c}}, \mathbf{K}$ & $\mathbf{P}_{\mathbf{c}}, \mathbf{b a r}$ & $\mathbf{\Delta H}_{\mathbf{2 9 8}}^{\mathbf{0}}, \mathbf{J} / \mathbf{m o l}$ & $\mathbf{G}^{\mathbf{0}} \mathbf{2 9 8}, \mathbf{J} / \mathbf{m o l}$ \\
\hline $\mathrm{H}_{2}$ & -0.2160 & 33.19 & 13.13 & 0 & 0 \\
$\mathrm{C}_{1}$ & 0.0120 & 190.60 & 45.99 & $-74,520$ & $-50,460$ \\
$\mathrm{C}_{2}$ & 0.1000 & 305.30 & 48.72 & $-83,820$ & $-31,855$ \\
$\mathrm{C}_{3}$ & 0.1520 & 369.80 & 42.48 & $-104,680$ & $-24,290$ \\
$\mathrm{C}_{4}$ & 0.2000 & 425.10 & 37.96 & $-125,790$ & $-16,570$ \\
$\mathrm{C}_{5}$ & 0.2520 & 469.70 & 33.70 & $-146,760$ & -8650 \\
$\mathrm{ip}_{6}$ & 0.3010 & 507.60 & 30.25 & $-174,300^{*}$ & $-2800^{*}$ \\
$\mathrm{ip}_{7}$ & 0.3500 & 540.20 & 27.40 & $-196,200 *$ & $56200^{*}$ \\
$\mathrm{ip}_{8}+$ & 0.4000 & 568.70 & 24.90 & $-215,500 *$ & $14,040^{*}$ \\
$\mathrm{np}_{6}$ & 0.2774 & 497.50 & 30.05 & $-166,920$ & 150 \\
$\mathrm{np}_{7}$ & 0.3277 & 530.37 & 27.34 & $-187,780$ & 8260 \\
$\mathrm{np}_{8}+$ & 0.3772 & 559.64 & 24.84 & $-208,750$ & 16,260 \\
$\mathrm{~N}_{6}$ & 0.2300 & 532.80 & 37.85 & $-108,100 *$ & $36,190 *$ \\
$\mathrm{~N}_{7}$ & 0.2350 & 572.2 & 34.71 & $-154,770$ & 27,480 \\
$\mathrm{~N}_{8}+$ & 0.2455 & 609.15 & 30.40 & $-172,600 *$ & $40,930 *$ \\
$\mathrm{~A}_{6}$ & 0.2100 & 562.20 & 48.98 & 82,930 & 129,665 \\
$\mathrm{~A}_{7}$ & 0.2620 & 591.80 & 41.06 & 50,170 & 122,050 \\
$\mathrm{~A}_{8}+$ & 0.3030 & 617.20 & 36.06 & 29,920 & 130,890 \\
\hline
\end{tabular}

* Taken from Chemical and Physical Properties by Cheméo [23].

Table 3. Constants for ideal gas heat capacity [24].

\begin{tabular}{|c|c|c|c|c|c|}
\hline \multirow[b]{2}{*}{ Compound } & \multicolumn{5}{|c|}{$\frac{\Delta C_{P}^{o}}{R}=\Delta A+\Delta B T+\Delta C T^{2}+\Delta D T^{3}+\Delta E T^{4}$} \\
\hline & A & $\mathrm{B} \times 10^{3}$ & $C \times 10^{6}$ & $\mathrm{D} \times 10^{10}$ & $E \times 10^{14}$ \\
\hline $\mathrm{C}$ & -0.50686 & 6.45776 & -4.70494 & 15.59118 & -19.04428 \\
\hline $\mathrm{H}_{2}$ & 3.24631 & 1.43467 & -2.89398 & 25.8003 & -73.9095 \\
\hline $\mathrm{C}_{1}$ & 4.34610 & -6.14488 & 26.62607 & -219.29980 & 588.89965 \\
\hline $\mathrm{C}_{2}$ & 4.00447 & -1.33847 & 42.86416 & -452.24460 & 1440.48530 \\
\hline $\mathrm{C}_{3}$ & 3.55751 & 10.07312 & 39.13602 & -475.72200 & 1578.16560 \\
\hline $\mathrm{C}_{4}$ & 2.91601 & 28.06907 & 15.37435 & -292.92550 & 1028.04620 \\
\hline $\mathrm{C}_{5}$ & 4.06063 & 29.87141 & 30.46993 & -461.35230 & 1559.89710 \\
\hline $\mathrm{ip}_{6}$ & 0.44073 & 60.77573 & -10.93570 & -180.70573 & 833.40865 \\
\hline $\mathrm{ip}_{7}$ & 0.57808 & 70.71556 & -15.00679 & -187.48705 & 899.92106 \\
\hline $\mathrm{ip}_{8}+$ & 0.92650 & 78.42561 & -11.24742 & -281.97592 & 1265.61161 \\
\hline $\mathrm{np}_{6}$ & 3.89054 & 41.42970 & 24.35860 & -457.52220 & 1599.41000 \\
\hline $\mathrm{np}_{7}$ & 4.52739 & 47.36877 & 31.09932 & -570.22085 & 1999.68224 \\
\hline$n p_{8}+$ & 4.47277 & 57.81747 & 29.07465 & -621.09106 & 2265.33690 \\
\hline $\mathrm{N}_{6}$ & -6.81073 & 80.58175 & -50.42977 & 141.93915 & -107.77270 \\
\hline $\mathrm{N}_{7}$ & -8.75751 & 100.20540 & -62.47659 & 169.33320 & -123.27361 \\
\hline $\mathrm{N}_{8}+$ & -5.50074 & 91.59292 & -26.04906 & -192.84542 & 1021.80248 \\
\hline $\mathrm{A}_{6}$ & -7.29786 & 75.33056 & -69.66390 & 336.46848 & -660.39655 \\
\hline $\mathrm{A}_{7}$ & -2.46286 & 57.69575 & -19.66557 & -106.61110 & -654.52596 \\
\hline $\mathrm{A}_{8}+$ & 4.72510 & 9.02760 & 141.18870 & -1989.23470 & 8167.18050 \\
\hline
\end{tabular}

The fmincon Matlab function was used to find the $n_{i}$ set that minimizes the total Gibbs free energy (Equation (1)), constrained to the elemental balances (of Equation (2)), and the 
$z$ function (Equation (5)). To evaluate the equilibrium, we use the molar flow composition at the inlet of the catalytic naphtha reforming process given in Table 4.

Table 4. Molar composition of the feed flow rate [25].

\begin{tabular}{cccccc}
\hline Model Compound & Molar Flow kmol/h & mol\% & Model Compound & Molar Flow kmol/h & mol\% \\
\hline $\mathrm{H}_{2}$ & 4173.8 & 69.69 & $\mathrm{ip}_{6}$ & 4.53 & 0.08 \\
$\mathrm{C}_{1}$ & 579.25 & 9.67 & $\mathrm{ip}_{7}$ & 52.80 & 0.88 \\
$\mathrm{C}_{2}$ & 292.33 & 4.88 & $\mathrm{ip}_{8}$ & 143.11 & 2.39 \\
$\mathrm{C}_{3}$ & 232.78 & 3.89 & $\mathrm{~N}_{6}$ & 1.16 & 0.02 \\
$\mathrm{C}_{4}$ & 113.68 & 1.90 & $\mathrm{~N}_{7}$ & 7.94 & 0.13 \\
$\mathrm{C}_{5}$ & 21.66 & 0.36 & $\mathrm{~N}_{8}$ & 18.35 & 0.31 \\
$\mathrm{np}_{6}$ & 15.83 & 0.26 & $\mathrm{~A}_{6}$ & 88.50 & 1.48 \\
$\mathrm{np}_{7}$ & 65.95 & 1.10 & $\mathrm{~A}_{7}$ & 81.02 & 1.35 \\
$\mathrm{np}_{8}+$ & 91.93 & 1.53 & $\mathrm{~A}_{8}$ & 4.60 & 0.08 \\
\hline
\end{tabular}

\subsection{Composition of the Catalytic Reforming Products}

Experimental results and ample plant experience have shown that catalytic naphtha reforming reactions are quite sensitive to operating temperature and pressure and on the hydrogen to hydrocarbon ratio $\left(\mathrm{H}_{2} / \mathrm{HC}\right)$. However, their effect on the various reforming reactions can differ. A simplified classification of the main reactions that take place during naphtha reforming is exemplified in Figure 1 and consist of: (a) Naphtenes dehydrogenation to aromatics, (b) alkyl cyclopentanes dehydroisomerization to aromatics, (c) alkanes dehydrocyclization to aromatics, (d) n-alkanes isomerization to branched alkanes, and (e) cracking reactions leading to lower carbon products with regard to the reactants [26]. These reactions are not affected in the same way by the operating conditions, while reactions that form aromatics (Figure $1 \mathrm{a}-\mathrm{c}$ ) are highly endothermic and thermodynamically benefit from higher temperatures and lower hydrogen partial pressures, operating under such conditions will clearly have negative effects on catalyst deactivation by coke deposition. Furthermore, exothermic reactions such as paraffin isomerization to alkenes and hydrocracking and hydrogenolysis (Figure 1e,d) will be facilitated by lower temperatures and the latter higher hydrogen partial pressure. Therefore, it is evident that the mutual interference of the operating factors on the main reactions makes naphtha reforming a complicated process.

For the simulation of catalytic naphtha reforming, we used the kinetic model reported by Arani et al., 2009, and the naphtha composition given in Table 4. In the kinetic model, $\mathrm{C}_{1}-\mathrm{C}_{5}$ hydrocarbons are considered light paraffins. The $\mathrm{C}_{6}$ to $\mathrm{C}_{8+}$ naphtha cuts are labeled as iso-paraffins, normal paraffins, and naphthenes aromatics. In reaction network, the reversible reactions of iso-paraffins produce normal paraffins, normal paraffins react to form naphthenes, and naphthenes form aromatics. Light paraffins are formed from the irreversible hydrocracking reactions of the iso-paraffins and aromatic fractions. The main difference between Arani et al. and this work is that in the first, the mole fractions of naphtha cuts with more than eight carbon numbers are lumped together, while we assume that a model compound can effectively represent eight carbon cuts.

The reaction section is split into three catalytic reactors. A furnace heats the feedstock back to the desired temperature to maintain an appropriate temperature between each reactor. Reactors are of different sizes, with the smallest one located in the first position and the largest one in the last. The typical reactor inlet temperature is around $774 \mathrm{~K}$, and the typical pressure is around $2.8 \mathrm{MPa}$.

A typical $\mathrm{Pt} / \mathrm{Al}_{2} \mathrm{O}_{3}$ catalyst promotes the reforming reactions. Both $\mathrm{Pt}$ and Alumina provide a different role in the reforming reactions. The metal sites catalyze hydrocarbons ${ }^{\prime}$ hydrogenation and dehydrogenation reactions, while the alumina's acid sites are known to catalyze hydrocarbon rearrangements reactions [26]. 
(a)<smiles>C1CCCCC1</smiles>

(b)<smiles>CC1CCCC1</smiles>

(c)

(d)

$$
\text { n- } \mathrm{C}_{7} \mathrm{H}_{16}
$$

n- $\mathrm{C}_{7} \mathrm{H}_{16}$<smiles>Cc1ccccc1</smiles>

$\rightleftharpoons$<smiles>c1ccccc1</smiles>

$+3 \mathrm{H}_{2}$

$\rightleftharpoons$<smiles>c1ccccc1</smiles><smiles>Cc1ccccc1</smiles>

$i-\mathrm{C}_{7} \mathrm{H}_{16}$

$\rightleftharpoons$

$$
+\mathrm{H}_{2}
$$$$
\rightleftharpoons
$$

$+4 \mathrm{H}_{2}$

Figure 1. Catalytic reforming reactions. (a) Naphtenes dehydrogenation to aromatics, (b) alkyl cyclopentanes dehydroisomerization to aromatics, (c) alkanes dehydrocyclization to aromatics, (d) nalkanes isomerization to branched alkanes, and (e) cracking reactions to lower carbon products.

Tables $5-8$ summarize the expected reforming reactions according to the model compounds given in Table 1.

Table 5. Isomerization of paraffins.

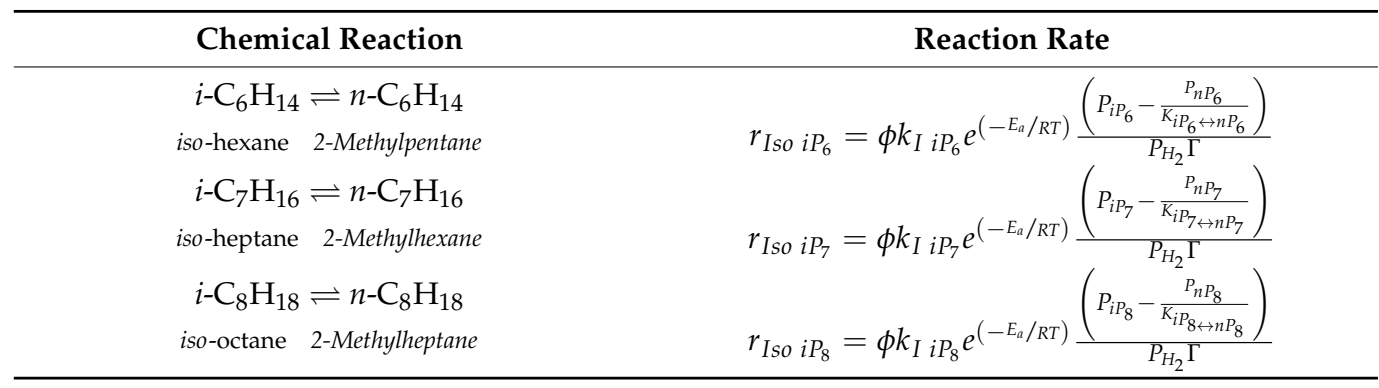

\begin{tabular}{|c|c|c|c|c|}
\hline \multicolumn{4}{|c|}{ Chemical Reaction } & Reaction Rate \\
\hline $\begin{array}{l}\mathrm{C}_{6} \mathrm{H}_{14} \\
n \text {-hexane }\end{array}$ & $\rightleftharpoons$ & $\begin{array}{c}\mathrm{C}_{6} \mathrm{H}_{12} \\
\text { Methylcyclopentane }\end{array}$ & $+\mathrm{H}_{2}$ & $r_{D H C} n P_{6}=\phi k_{D H C} n P_{6} e^{\left(-E_{a} / R T\right)} \frac{\left(P_{n P_{6}}-\frac{P_{N_{6}} P_{H}}{K_{n P_{6}} \leftrightarrow N_{6}}\right)}{P_{H} \Gamma}$ \\
\hline $\begin{array}{l}\mathrm{C}_{7} \mathrm{H}_{16} \\
\text { n-heptane }\end{array}$ & $\rightleftharpoons$ & $\begin{array}{l}\quad \mathrm{C}_{7} \mathrm{H}_{14} \\
\text { Methylcyclohexane }\end{array}$ & $+\mathrm{H}_{2}$ & $r_{D H C} n P_{7}=\phi k_{D H C} n P_{7} e^{\left(-E_{a} / R T\right)} \frac{\left(P_{n P_{7}-\frac{N_{7}}{K_{n P_{7}}}}\right.}{P_{\mathrm{H}_{2}} \Gamma}$ \\
\hline $\begin{array}{l}\mathrm{C}_{8} \mathrm{H}_{18} \\
n \text {-octane }\end{array}$ & $\rightleftharpoons$ & $\begin{array}{l}\quad \mathrm{C}_{8} \mathrm{H}_{16} \\
\text { Ethylcyclohexane }\end{array}$ & $+\mathrm{H}_{2}$ & $r_{D H C} n P_{8}=\phi k_{D H C} n P_{8} e^{\left(-E_{a} / R T\right)} \frac{\left(P_{n P_{8}}-\frac{P_{N_{8}} P_{H_{2}}}{K_{n P_{8}} \leftrightarrow N_{8}}\right)}{P_{H_{2}} \Gamma}$ \\
\hline
\end{tabular}

Table 6. Dehydrocyclization of paraffins. 
Table 7. Dehydrogenation of naphthenes.

\begin{tabular}{|c|c|c|c|c|}
\hline \multicolumn{4}{|c|}{ Chemical Reaction } & Reaction Rate \\
\hline $\mathrm{C}_{6} \mathrm{H}_{12}$ & $\longrightarrow$ & $\mathrm{C}_{6} \mathrm{H}_{6}$ & $+3 \mathrm{H}$ & \\
\hline Methylcyclopentane & - & Benzene & $311_{2}$ & $r_{D H N_{6}}=\phi k_{D H N_{6}} e^{\left(-E_{a} / R T\right)}$ \\
\hline $\mathrm{C}_{7} \mathrm{H}_{14}$ & $\rightleftharpoons$ & $\mathrm{C}_{7} \mathrm{H}_{8}$ & $+3 \mathrm{H}_{2}$ & \\
\hline Methylcyclohexane & & Toluene & & $r_{D H N_{7}}=\phi k_{D H N_{7}} e^{\left(-E_{a} / R T\right)}$ \\
\hline $\begin{array}{l}\quad \mathrm{C}_{8} \mathrm{H}_{16} \\
\text { Ethylcyclohexane }\end{array}$ & $\rightleftharpoons$ & $\begin{array}{c}\mathrm{C}_{8} \mathrm{H}_{10} \\
\text { Ethylbenzene }\end{array}$ & $+3 \mathrm{H}_{2}$ & $r_{D H N_{8}}=\phi k_{D H N_{8}} e^{\left(-E_{a} / R T\right)} \frac{\left(P_{\left.N_{8}-\frac{K_{N_{8}} \leftrightarrow A_{8}}{K_{2}}\right)}\right.}{P_{H_{2}} \Gamma}$ \\
\hline
\end{tabular}

Table 8. Hydrocracking reactions.

\begin{tabular}{|c|c|c|c|c|}
\hline \multicolumn{4}{|c|}{ Chemical Reaction } & Reaction Rate \\
\hline$n-\mathrm{C}_{5} \mathrm{H}_{12}+\mathrm{H}_{2}$ & $2 \rightarrow$ & \multicolumn{2}{|c|}{$1 / 2 \mathrm{CH}_{4}+1 / 2 \mathrm{C}_{2} \mathrm{H}_{6}+1 / 2 \mathrm{C}_{3} \mathrm{H}_{8}+1 / 2 \mathrm{C}_{4} \mathrm{H}_{10}$} & $r_{H D C \text { rack } i P_{5}}=\phi k_{H D C r a c k i P_{5}} e^{\left(-E_{a} / R T\right)} \frac{P_{i P_{5}}}{\Gamma}$ \\
\hline$i-\mathrm{C}_{6} \mathrm{H}_{14}+\mathrm{H}_{2}$ & $\rightarrow$ & \multirow{3}{*}{\multicolumn{2}{|c|}{$\begin{array}{c}1 / 3 \mathrm{CH}_{4}+1 / 3 \mathrm{C}_{2} \mathrm{H}_{6}+2 / 3 \mathrm{C}_{3} \mathrm{H}_{8}+1 / 3 \mathrm{C}_{4} \mathrm{H}_{10}+1 / 3 \mathrm{C}_{5} \mathrm{H}_{12} \\
1 / 3 \mathrm{CH}_{4}+1 / 3 \mathrm{C}_{2} \mathrm{H}_{6}+1 / 3 \mathrm{C}_{3} \mathrm{H}_{8}+1 / 3 \mathrm{C}_{4} \mathrm{H}_{10}+1 / 3 \mathrm{C}_{5} \mathrm{H}_{12}+1 / 3 i-\mathrm{C}_{6} \mathrm{H}_{14} \\
1 / 4 \mathrm{CH}_{4}+1 / 4 \mathrm{C}_{2} \mathrm{H}_{6}+1 / 4 \mathrm{C}_{3} \mathrm{H}_{8}+1 / 2 \mathrm{C}_{4} \mathrm{H}_{10}+1 / 4 \mathrm{C}_{5} \mathrm{H}_{12}+1 / 4 i-\mathrm{C}_{6} \mathrm{H}_{14}+ \\
1 / 4 i-\mathrm{C}_{7} \mathrm{H}_{16}\end{array}$}} & $r_{H D C \text { rack } i P_{6}}=\phi k_{H D C \text { rack } i P_{6}} e^{\left(-E_{a} / R T\right)} \frac{P_{i P_{6}}}{\Gamma}$ \\
\hline$i-\mathrm{C}_{7} \mathrm{H}_{16}+\mathrm{H}_{2}$ & $\rightarrow$ & & & $r_{H D C \text { rack } i P_{7}}=\phi k_{H D C \text { rack } i P_{7}} e^{\left(-E_{a} / R T\right)} \frac{P_{i P_{7}}^{1}}{\Gamma}$ \\
\hline$i-\mathrm{C}_{8} \mathrm{H}_{18}+\mathrm{H}_{2}$ & $\rightarrow$ & & & $r_{H D C r a c k i P_{8}}=\phi k_{H D C r a c k i P_{8}} e^{\left(-E_{a} / R T\right)} \frac{P_{i P_{8}}}{\Gamma}$ \\
\hline $\mathrm{C}_{7} \mathrm{H}_{8}$ Toluene & $+\mathrm{H}_{2} \rightarrow$ & $\mathrm{C}_{6} \mathrm{H}_{6}$ Benzene & $+\mathrm{CH}_{4}$ & $r_{H D C \text { rack } A_{7}}=\phi k_{H D C \text { rack } A_{7}} e^{\left(-E_{a} / R T\right)} \frac{P_{A_{7}}}{\Gamma}$ \\
\hline $\begin{array}{l}\quad \mathrm{C}_{8} \mathrm{H}_{10} \\
\text { Ethylbenzene }\end{array}$ & $+\mathrm{H}_{2} \rightarrow$ & $\begin{array}{c}1 / 2 \mathrm{C}_{7} \mathrm{H}_{8} \text { Toluene }+1 / 2 \mathrm{C}_{6} \mathrm{H}_{6} \\
\text { Benzene }\end{array}$ & $\begin{array}{l}+1 / 2 \mathrm{CH}_{4} \\
+1 / 2 \mathrm{C}_{2} \mathrm{H}_{6}\end{array}$ & $r_{H D C r a c k} A_{8}=\phi k_{H D C r a c k} A_{8} e^{\left(-E_{a} / R T\right)} \frac{P_{A_{8}}}{\Gamma}$ \\
\hline
\end{tabular}

The catalyst deactivation function is as follow:

$$
\phi=\left[-k_{d} e^{\left(-\frac{E_{d}}{R}\left[\frac{1}{T}-\frac{1}{T_{R}}\right]\right)}(-m+1)(t)+1\right]^{\left(\frac{1}{-m+1}\right)}
$$

The kinetic parameters for the reaction rate expressions given in Tables 5-8 and the deactivation parameters for Equation (15) were taken from Arani et al., 2009.

Pressure drops were calculated according to Ergun's Equation.

$$
\frac{d P}{d w}=-\frac{G}{\rho d_{p} \varphi^{3}}\left[\frac{150(1-\varphi) \mu}{d_{p}}+\frac{1}{A_{c} \rho_{c}}\right]
$$

Temperature variations in the catalytic bed were attained by the following differential equation:

$$
\frac{d T}{d w}=\sum_{j=1}^{n_{r}} r_{j} \Delta H_{R_{j}} / \sum_{i=1}^{n_{C}} F_{i} C_{p_{i}}
$$

Since radial and axial dispersion effects are minimal under usual reactor operating conditions [27], the material balances were defined in terms of molar flow by assuming a perfect plug flow reactor.

$$
\begin{gathered}
\frac{d F_{H_{2}}}{d w}=\left[r_{D H C n P_{6}}\right]+\left[r_{D H C} n P_{7}\right]+\left[r_{D H C} n P_{8}\right]+(3)\left[r_{D H N_{6}}\right]+(3)\left[r_{D H N_{7}}\right]+(3)\left[r_{D H N_{8}}\right]-\left[r_{H D C r a c k i P_{5}}\right] \\
-\left[r_{H D C \text { rack } i P_{6}}\right]-\left[r_{H D C r a c k i P_{7}}\right]-\left[r_{H D C r a c k i P_{8}}\right]-\left[r_{H D C r a c k} A_{7}\right]-\left[r_{H D C r a c k} A_{8}\right]
\end{gathered}
$$

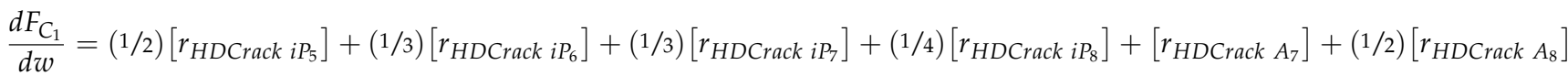

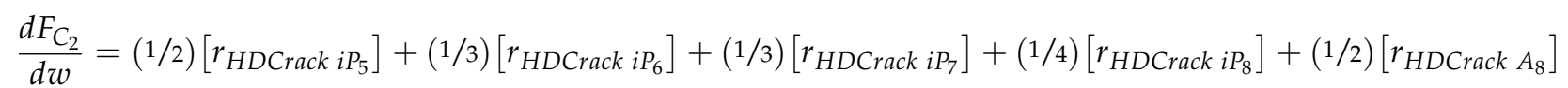

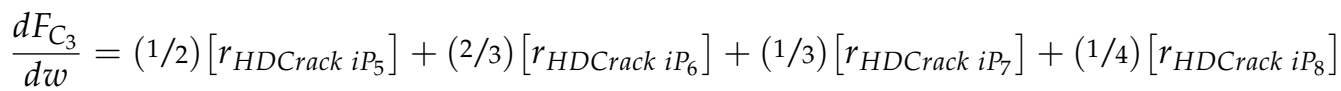




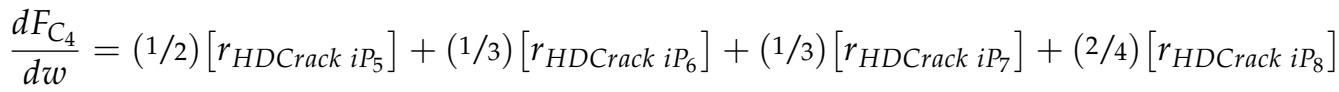

$$
\begin{aligned}
& \frac{d F_{C_{5}}}{d w}=-\left[r_{H D C r a c k} n P_{5}\right]+(1 / 3)\left[r_{H D C r a c k i P_{6}}\right]+(1 / 3)\left[r_{H D C r a c k i P_{7}}\right]+(1 / 4)\left[r_{H D C r a c k i} P_{8}\right] \\
& \frac{d F_{n P_{6}}}{d w}=\left[r_{\text {Iso } i P_{6}}\right]-\left[r_{D H C} n P_{6}\right] \\
& \frac{d F_{n P_{7}}}{d w}=(1)\left[r_{\text {Iso } i P_{7}}\right]-(1)\left[r_{D H C} n P_{7}\right] \\
& \frac{d F_{n P_{8}}}{d w}=\left[r_{\text {Iso } i P_{8}}\right]-\left[r_{D H C} n P_{8}\right]
\end{aligned}
$$

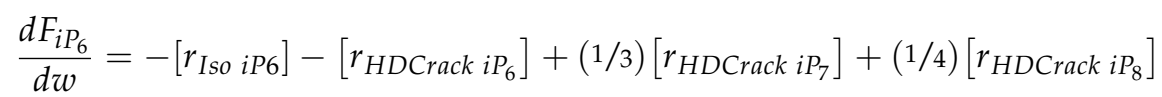

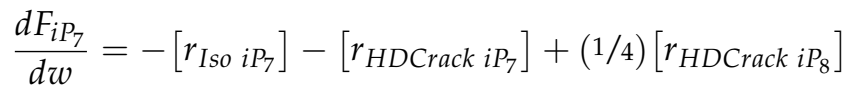

$$
\begin{aligned}
& \frac{d F_{i P_{8}}}{d w}=-\left[r_{\text {Iso }} i P_{8}\right]-\left[r_{H D C r a c k} i P_{8}\right] \\
& \frac{d F_{N_{6}}}{d w}=\left[\begin{array}{lll}
r_{D H C} P_{6} &
\end{array}-\left[r_{D H} N_{6}\right]\right. \\
& \frac{d F_{N_{7}}}{d w}=\left[r_{D H C} n P_{7}\right]-\left[r_{D H N_{7}}\right] \\
& \frac{d F_{N_{8}}}{d w}=\left[r_{D H C} n P_{8}\right]-\left[r_{D H N_{8}}\right] \\
& \frac{d F_{A_{6}}}{d w}=\left[r_{D H N_{6}}\right]+\left[r_{H D C r a c k} A_{7}\right]+(1 / 2)\left[r_{\text {HDCrack }} A_{8}\right] \\
& \frac{d F_{A_{7}}}{d w}=\left[r_{D H N_{7}}\right]-\left[r_{H D C r a c k} A_{7}\right]+(1 / 2)\left[r_{H D C r a c k} A_{8}\right] \\
& \frac{d F_{A_{8+}}}{d w}=\left[r_{D H N_{8}}\right]-\left[r_{H D C r a c k} A_{8}\right]
\end{aligned}
$$

To validate the assumption of the model compounds given in Table 1, Equations (6)-(26) were solved simultaneously by using the Runge-Kutta fourth order method to simulate the industrial data reported for a catalytic naphtha reforming process given in [25].

The results are given in Table 9 . We satisfactorily predict the aromatic fractions and for most cases, the absolute error is below $5 \%$ when compared with the plant data. For the cases where the error is higher than $5 \%$, we can observe that it is close to the error reported by Arani et al., 2009.

Table 9. Model prediction of the industrial plant data.

\begin{tabular}{cccccc}
\hline & \multicolumn{3}{c}{ Molar Composition } & \multicolumn{2}{c}{$\%$ Abs Error } \\
& Plant Data & Arani et al. & This Work & Arani et al. & This Work \\
\hline $\mathrm{H}_{2}$ & 68.89 & 69.02 & 68.30 & 0.19 & 0.85 \\
$\mathrm{C}_{1}$ & 9.62 & 9.56 & 9.87 & 0.62 & 2.64 \\
$\mathrm{C}_{2}$ & 5.05 & 5.29 & 5.12 & 4.75 & 1.40 \\
$\mathrm{C}_{3}$ & 4.53 & 4.36 & 4.71 & 3.75 & 4.04 \\
$\mathrm{C}_{4}$ & 2.89 & 2.87 & 2.95 & 0.69 & 2.12 \\
$\mathrm{C}_{5}$ & 1.3 & 1.16 & 1.19 & 10.77 & 8.81 \\
$\mathrm{np}_{6}$ & 0.27 & 0.23 & 0.24 & 14.81 & 10.27 \\
$\mathrm{np}_{7}$ & 0.26 & 0.26 & 0.27 & 0.0 & 4.52 \\
$\mathrm{np}_{8+}$ & 0.08 & 0.07 & 0.07 & 12.5 & 9.47 \\
$\mathrm{ip}_{6}$ & 0.63 & 0.67 & 0.65 & 6.35 & 3.83 \\
\hline
\end{tabular}


Table 9. Cont.

\begin{tabular}{cccccc}
\hline & \multicolumn{3}{c}{ Molar Composition } & \multicolumn{2}{c}{ \% Abs Error } \\
& Plant Data & Arani et al. & This Work & Arani et al. & This Work \\
\hline $\mathrm{ip}_{7}$ & 0.9 & 0.82 & 0.99 & 8.89 & 10.42 \\
$\mathrm{ip}_{8+}$ & 0.32 & 0.36 & 0.35 & 12.5 & 10.64 \\
$\mathrm{~N}_{6-10}$ & 0.1 & 0.09 & 0.11 & 10.0 & 7.64 \\
$\mathrm{~A}_{6}$ & 0.38 & 0.44 & 0.40 & 15.79 & 4.35 \\
$\mathrm{~A}_{7}$ & 1.81 & 1.86 & 1.8 & 2.76 & 0.6 \\
$\mathrm{~A}_{8+}$ & 2.97 & 2.94 & 2.89 & 1.01 & 2.58 \\
\hline
\end{tabular}

\section{Results and Discussion}

Catalytic reformers are designed for flexibility in operation, and changes in operating parameters, such as temperature, pressure, and $\mathrm{H}_{2} / \mathrm{HC}$ ratio, which affect reformate quality and yield. Reformers generally consist of a series of reactors that operate at a different temperature. The weight average bed temperature (WAIT) is a parameter of everyday practice that refers to the sum of the inlet temperature to each reactor multiplied by the weight percent of the total catalyst in each reactor. Reaction temperatures are chosen to promote a catalyst activity that could counterbalance the catalyst deactivation rate. In this regard, maximum reaction temperatures are reported in the range 733-798 K. However, in order to optimize high octane products, some low-pressure processes operate at slightly higher temperatures. As reformate $\mathrm{RON}$ increases with reactor temperature, for instance, a RON range of 90-95, WAIT should increase approximately by a $2-3 \mathrm{~K} / \mathrm{RON}$ increase, depending on feedstock [25].

Operating pressure is an important parameter that influences product quality and yield. Reformer reactors operate in the 0.5 to $1.1 \mathrm{MPa}$ pressure range, and it is common practice that each of the reactors in series operates at different pressures. For instance, operation under a decreasing pressure scheme on one side increases aromatics and hydrogen yield, but on the other increases coke formation and hence, catalyst deactivation. It has been demonstrated that a decrease in pressure increases product yield. At a $100 \mathrm{RON}$ level, liquid yield increases or decreases by about 2 volume percent of charge per each $0.8 \mathrm{MPa}$ change in pressure [26].

Finally, the presence of hydrogen is essential to avoid catalyst deactivation and undesirable side reactions. However, operating at high hydrogen-to-hydrocarbon ratios implies increased energy costs from more significant hydrogen recycling rates. Therefore, the lower boundary is often dictated by the desired amount of hydrocracking and maximum acceptable catalyst deactivation to save energy. Former designs used $\mathrm{H}_{2} / \mathrm{HC}$ ratios in the range $8-10$ while modern reformers, that benefit from highly active catalysts, operate in the 2-5 range and $0.5-1.1 \mathrm{H}_{2}$ partial pressure range.

\subsection{Temperature Effect}

According to the equilibrium calculations, it can be seen in Figure 2c that aromatics and hydrogen formation are favored at temperatures higher than $800 \mathrm{~K}$. Moreover, paraffins, naphthenes, and $C_{2}-C_{5}$ are entirely consumed in the range of 600-1300 K. At temperatures lower than $800 \mathrm{~K}$, there is an important methane production (Figure 2a), while the hydrogen production is less than $1 \%$ (Figure 2c). Methane production is associated with the hydrocracking reactions, since they typically occur at temperatures in the range of 573-723 K [28-30]. Additionally, they demand a large amount of hydrogen, about $0.5-0.8 \mathrm{wt} \%$ relative to the feed, for saturating the cracking fractions [31]. At temperatures higher than $800 \mathrm{~K}$, the isomerization reaction of iso-paraffins to paraffins, the hydroacylation reactions of paraffins to naphthene, and the dehydrogenation of naphthenes are highly favored to increase aromatic production. 

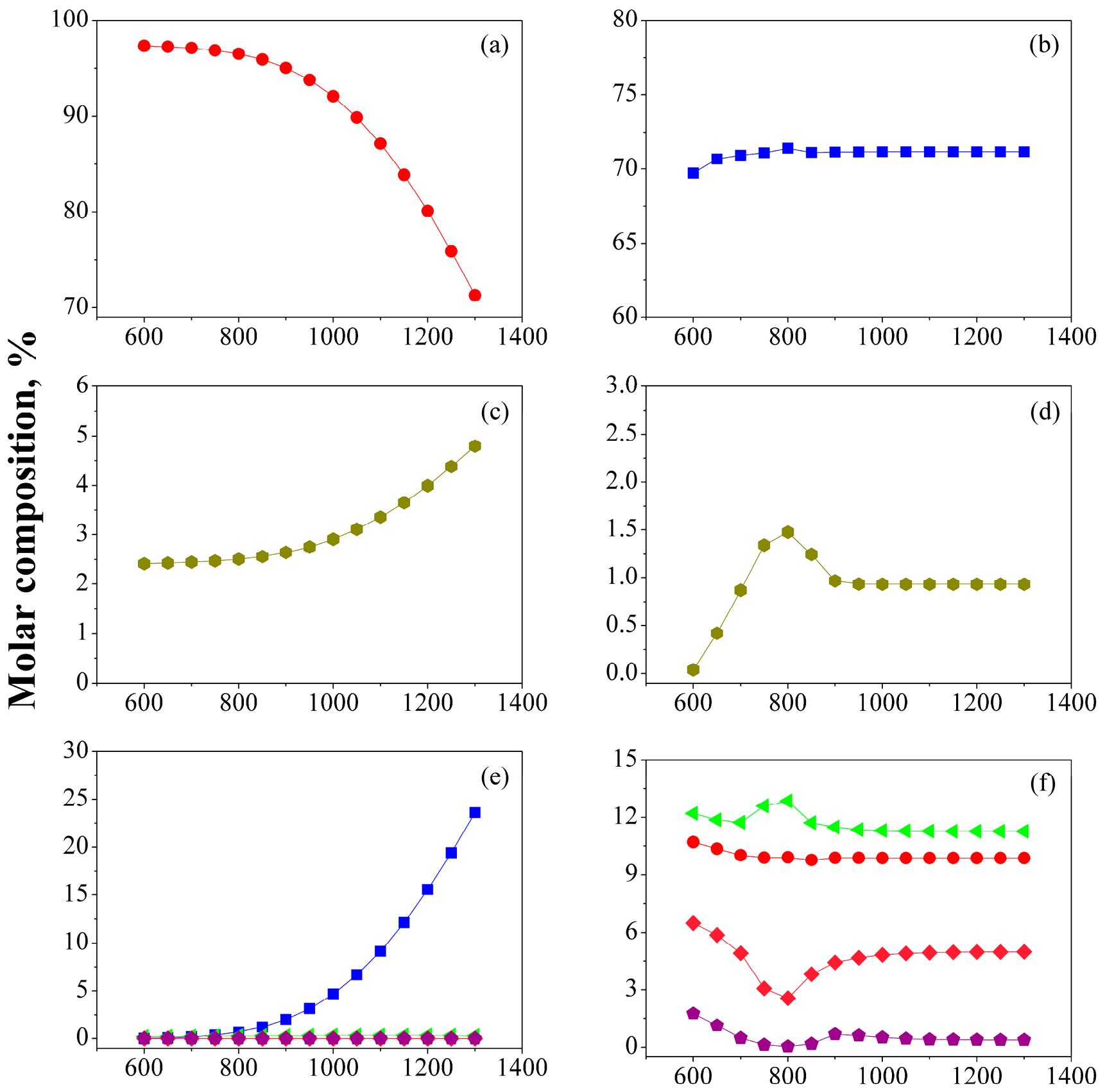

\section{Temperature, $\mathbf{K}$}

Figure 2. Effect of temperature on molar composition at $2.86 \mathrm{MPa}$ and $9.4 \mathrm{H}_{2} / \mathrm{HC}$ molar ratio: $(\mathbf{a}, \mathbf{c}, \mathbf{e})$ Equilibrium. (b,d,f) Catalytic. $(\bullet) \mathrm{CH}_{4},(\boldsymbol{\nabla}) \mathrm{H}_{2},(\Delta) \mathrm{C}_{2}-\mathrm{C}_{5},(\diamond)$ Paraffins, $(\boldsymbol{)})$ Naphthenes, ( Aromatics. 
The hydrogen production increase correlates to the dehydrogenation of naphthenes to aromatics, which boosts hydrogen production at temperatures higher than $900 \mathrm{~K}$ (Figure 2e). In Figure $2 \mathrm{a}$, it can also be observed that methane production decreases as reaction temperature increases, indicating that reforming reactions become more favored than hydrocracking reactions at such conditions.

On the other hand, we observed in Figure $2 \mathrm{~d}$ that for the catalytic reforming, there is a maximum in the production of the aromatics at $800 \mathrm{~K}$, which matches with the maximum observed in the hydrogen production (Figure $2 b$ ) and the minimum observed in the paraffins and naphthenes composition (Figure 2f). The molar composition of methane remains almost constant in the temperature range of 600 to $1300 \mathrm{~K}$. The $C_{2}-C_{5}$ production shows a maximum that agrees with the production of the aromatic. This confirmed that the dehydrogenation of naphthenes is favored by high reaction temperatures since they were almost wholly converted [32].

Whether or not a catalyst is present, thermodynamics determines the equilibrium composition of reactants and products. Nonetheless, the presence of a catalyst allows the system to reach equilibrium faster. Based on this, it can be said that the catalyst used in catalytic naphtha reforming can still be improved to increase aromatics production. At $800 \mathrm{~K}$, molar composition for this fraction is only $1.5 \%$ for the catalytic process (Figure $2 \mathrm{~d}$ ), while at equilibrium it is about $2.5 \%$ (Figure $2 \mathrm{c}$ ). Additionally, an increase in aromatics production will also result in an increase in hydrogen production.

\subsection{Pressure Effect}

It is shown in Figures 3 and 4 that high pressures at both thermodynamics and catalytic conditions are not favorable for the naphtha reforming process, which agrees with previous studies reported in the literature [20]. Higher pressures promote the formation of light hydrocarbons (Figure $3 a, b$ ), and the formation of $C_{1}-C_{5}$ gases (Figure $3 e, f$ ), which is mainly attributed to the hydrocracking reactions. This is confirmed by the increase in the hydrogen consumption observed in Figure 3c,d since such reactions consume high amounts of hydrogen [33].

It can be seen in Figure $4 a, c$ that at the equilibrium paraffins and naphthenes are wholly converted to their corresponding intermediate compound to finally produce aromatics. Conversely, in the catalytic process, we observed that paraffins and naphthenes reach a minimum at $800 \mathrm{~K}$ (Figure $4 \mathrm{~b}, \mathrm{~d}$ ), which agrees with the maximum production of aromatic observed in Figure $4 \mathrm{f}$.

Dehydrocyclization and dehydrogenation are desired reactions, since they produce hydrogen, and both are favored by low pressure and high temperature [34]. We observe in Figure $4 \mathrm{~b}$ that the concentration of paraffin components increases as the pressure increases. This is probably because the dehydrocyclization reactions are favored at a higher reaction pressure and higher molecular weight of carbon number [32].

Figure 4e,f shows that low pressures favor aromatics production. The increase in pressure results in a lower rate of catalytic aromatization reactions [35], increasing naphthenes (Figure $4 \mathrm{~d}$ ) and decreasing aromatics (Figure 4f) composition. 

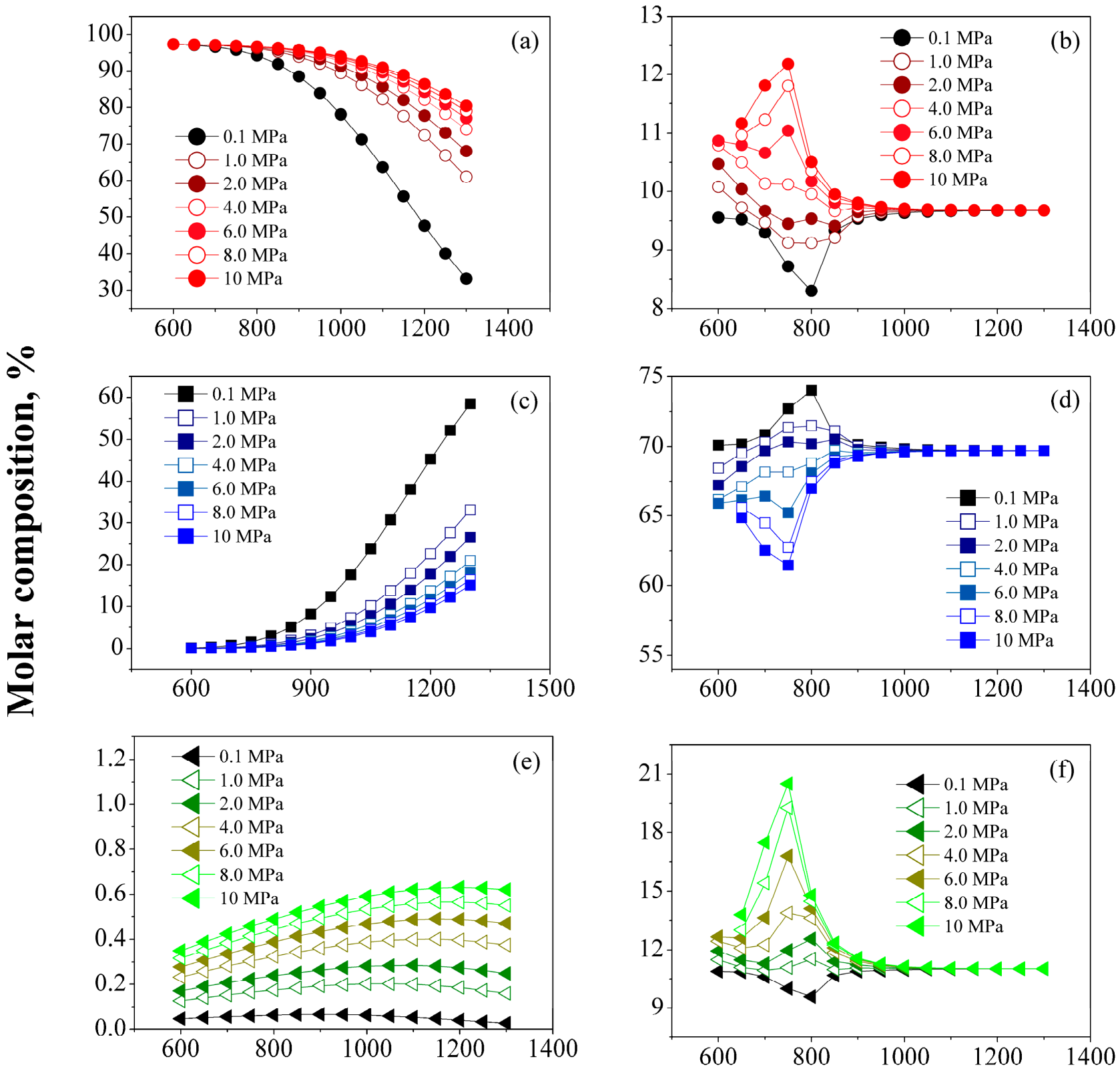

\section{Temperature, $\mathbf{K}$}

Figure 3. Effect of pressure on gas products: $(\mathbf{a}, \mathbf{c}, \mathbf{e})$ Equilibrium. (b,d,f) Catalytic. $(\mathbf{O} / \mathrm{O}) \mathrm{CH}_{4}$, $(\boldsymbol{\square} \square) \mathrm{H}_{2},(\triangleleft / \triangleleft) \mathrm{C}_{2}-\mathrm{C}_{5}$. 

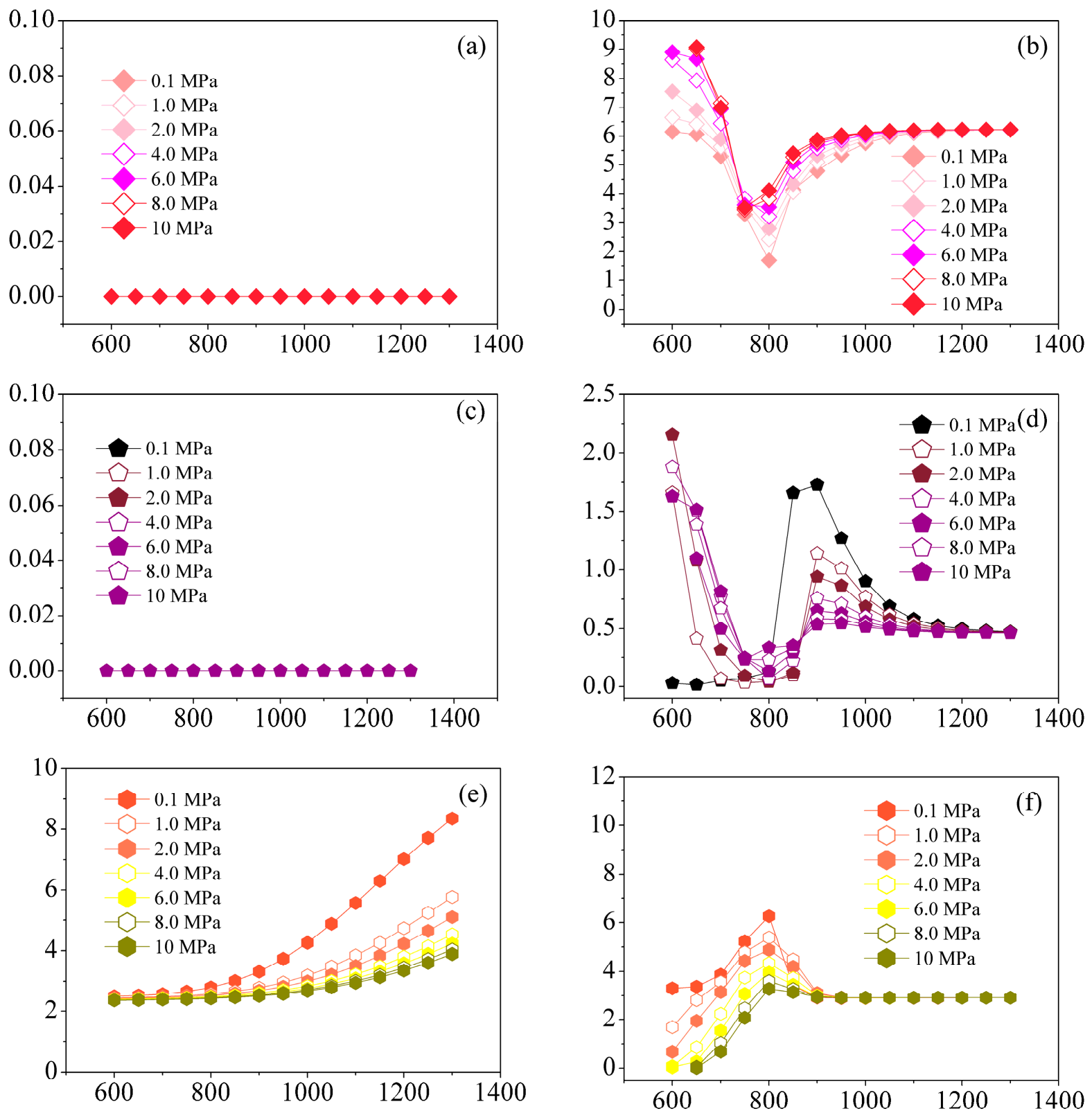

\section{Temperature, $\mathbf{K}$}

Figure 4. Effect of pressure on liquid products: (a,c,e) Equilibrium. $(\mathbf{b}, \mathbf{d}, \mathbf{f})$ Catalytic. $(\diamond / \diamond)$ Paraffins, $(\Delta / \triangle)$ Naphthenes, and $(\Delta / \square)$ Aromatics.

\subsection{Effect of the $\mathrm{H}_{2} / \mathrm{HC}$ Ratio}

The molar $\mathrm{H}_{2} / \mathrm{HC}$ ratio (R) effect is depicted in Figures 5 and 6 . We noted an increase in $\mathrm{CH}_{4}$ (Figure $5 \mathrm{a}, \mathrm{b}$ ) and $\mathrm{C}_{2}-\mathrm{C}_{5}$ gas production (Figure 5e,f) when the molar $\mathrm{H}_{2} / \mathrm{HC}$ ratio increased.

These indicate that a higher $\mathrm{R}$-value reduces aromatization and increases hydrocracking [25]. Nonetheless, the $\mathrm{C}_{2}-\mathrm{C}_{5}$ contribution is less than $1 \%$ at both $10 \mathrm{MPa}$ and $0.1 \mathrm{MPa}$ in the catalytic process (Figure $5 \mathrm{f}$ ).

An increase in the $\mathrm{H}_{2} / \mathrm{HC}$ promotes the hydrocracking of paraffins, which decreases paraffins composition when the R-value is increased (Figure $6 \mathrm{~b}$ ). This is confirmed in Figure $6 \mathrm{~d}$ since naphthenes's composition remains constant for all the $\mathrm{R}$ values at $800 \mathrm{~K}$, 
the temperature at which the production of the maximum aromatic was observed for the catalytic process (Figure 4f).

Figure $6 e, f$ depict that an increase in the R-value significantly decreases aromatic production at low and high pressures. At $800 \mathrm{~K}$, the production of the aromatic decreases about ten percentage points when the $\mathrm{H}_{2} / \mathrm{HC}$ ratio increases from 2 to 12 , at both 0.1 and $10 \mathrm{MPa}$.
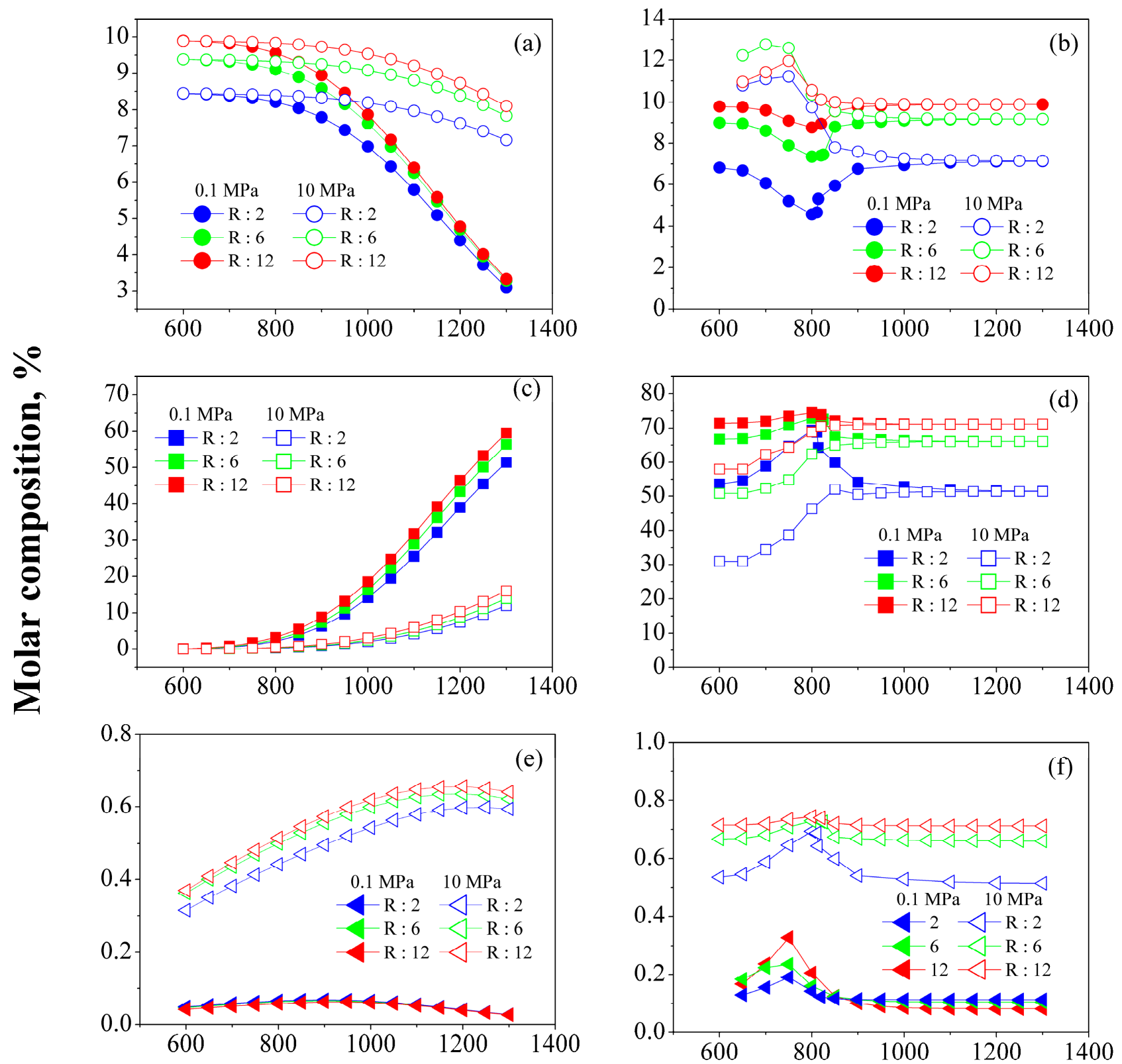

\section{Temperature, $\mathbf{K}$}

Figure 5. Effect of $\mathrm{H}_{2} / \mathrm{HC}$ molar ratio on gas products: (a,c,e) Equilibrium. (b,d,f) Catalytic. $(-/)$ $\mathrm{CH}_{4},(\mathbf{\square} / \square) \mathrm{H}_{2},(\triangleleft / \triangleleft) \mathrm{C}_{2}-\mathrm{C}_{5}$. 

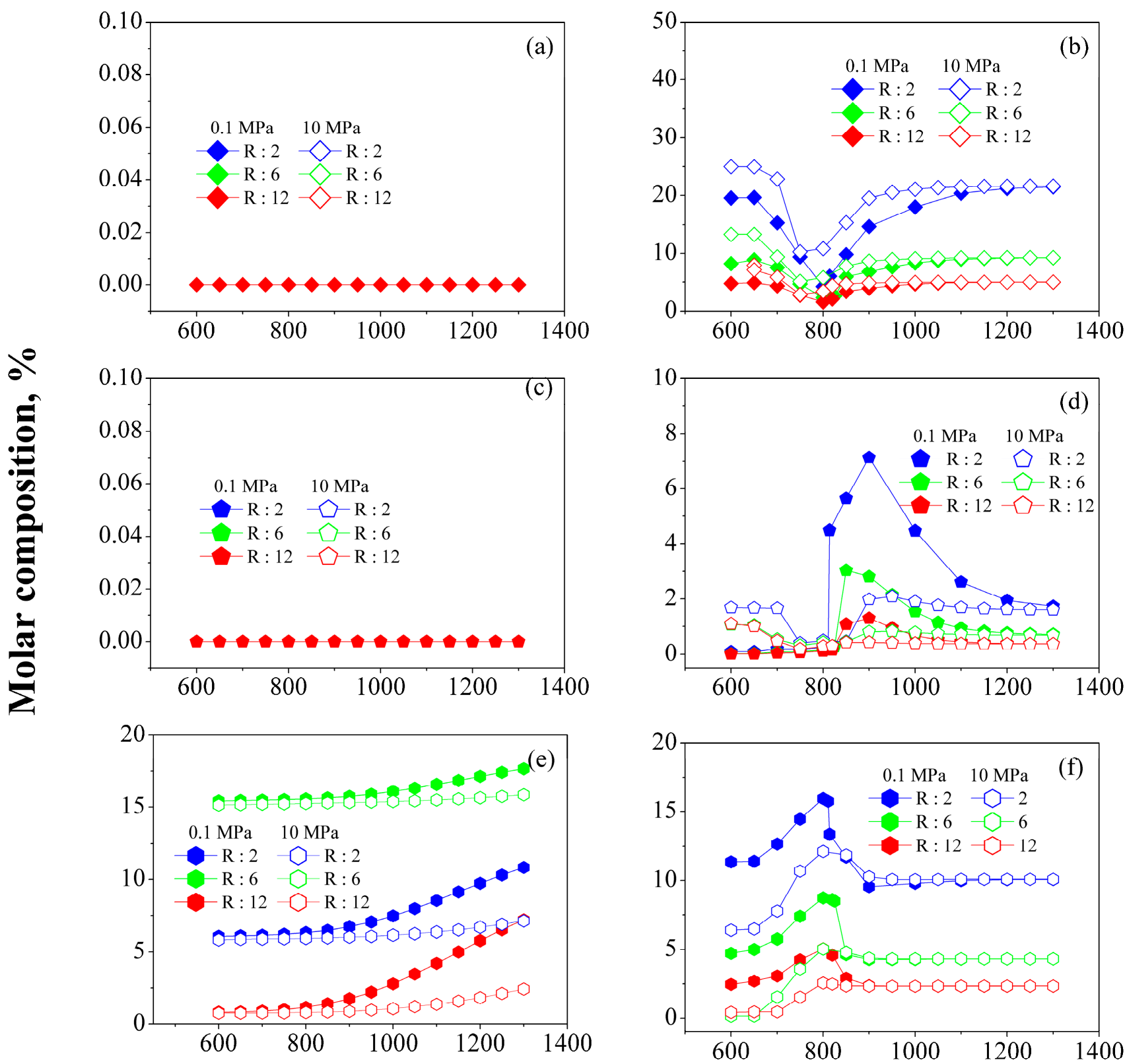

\section{Temperature, $\mathrm{K}$}

Figure 6. Effect of $\mathrm{H}_{2} / \mathrm{HC}$ molar ratio on liquid products: (a,c,e) Equilibrium. (b,d,f) Catalytic. $(\diamond / \diamond)$ Paraffins, $(\Delta / \bullet)$ Naphthenes, and $(\Delta)$ Aromatics.

\subsection{Aromatics Distribution}

In Figure 7, we present the effect of pressure and temperature on the aromatic distribution. We observed that, at the equilibrium, high temperatures favor the $\mathrm{A}_{6}$ aromatic production (Figure 7a), while low temperatures favor the production of $\mathrm{A}_{7}$ and $\mathrm{A}_{8+}$ aromatics (Figure 7c,e). Regarding the pressure, we found that low pressure favors the $A_{6}$ aromatic production (Figure $7 \mathrm{a}$ ), while high pressures favor the production of $A_{7}$ and $A_{8+}$ aromatics (Figure 7c,e). 

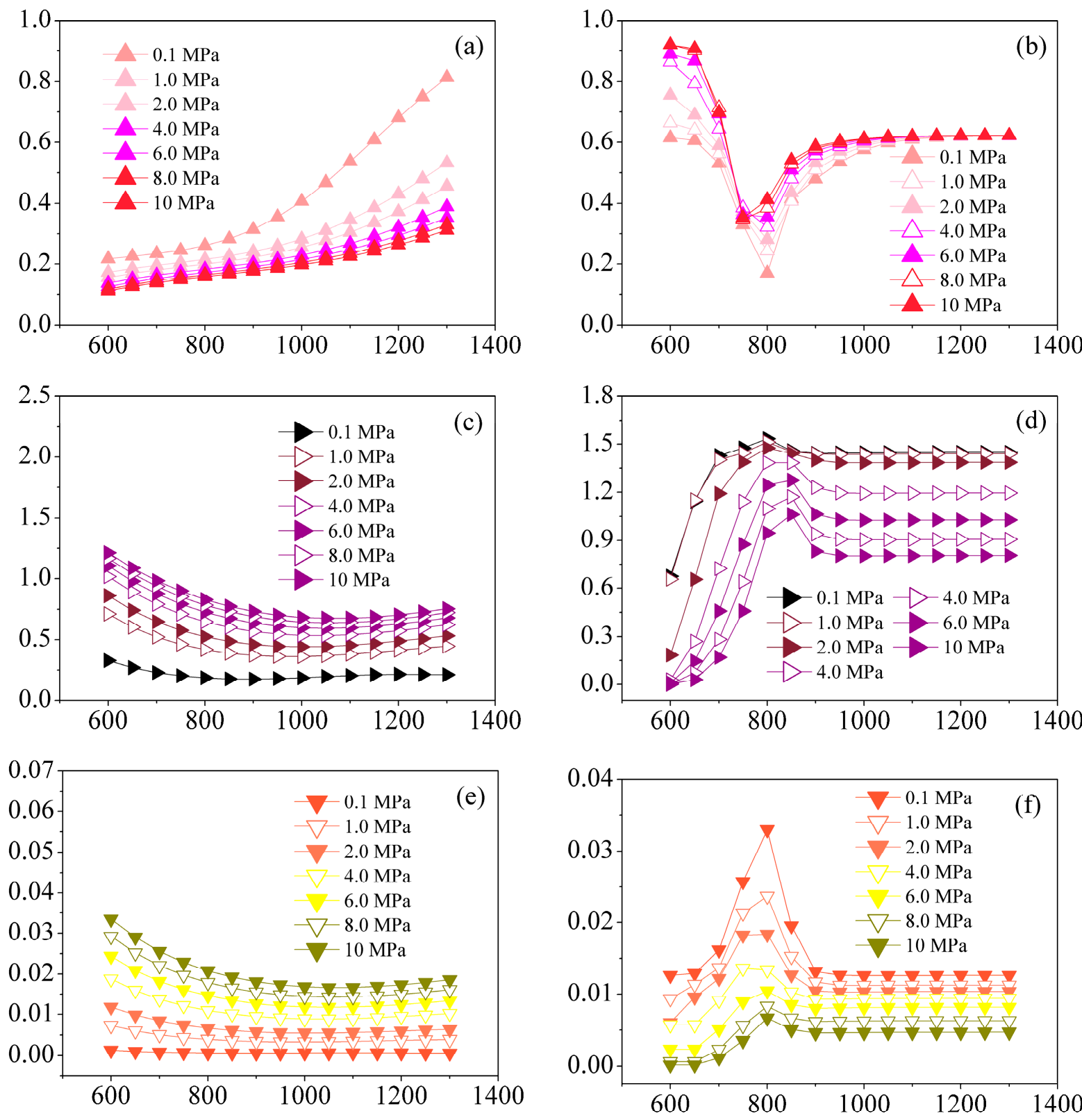

\section{Temperature, $\mathbf{K}$}

Figure 7. Effect of pressure on aromatics molar composition $\left(\mathrm{R}=9.4 \mathrm{H}_{2} / \mathrm{HC}\right)$ : (a,c,e) Equilibrium. $(\mathbf{b}, \mathbf{d}, \mathbf{f})$ Catalytic. $(\boldsymbol{\Lambda} / \triangle) \mathrm{C}_{6}$ Aromatics, $(\boldsymbol{\nabla} /) \mathrm{C}_{7}$ Aromatics, $(\boldsymbol{\nabla} / \nabla) \mathrm{C}_{8}$ Aromatics.

We analyzed the aromatic distribution at $800 \mathrm{~K}$ for the catalytic process, the temperature at which the maximum aromatic production was achieved. We observed in Figure $7 \mathrm{~b}$ that the $\mathrm{A}_{6}$ aromatic production increases, while $\mathrm{A}_{7}$ an $\mathrm{A}_{8+}$ aromatic production decrease when pressure is increased (Figure $7 \mathrm{~d}, \mathrm{f}$ ). It has been reported that $C_{7}$ and $C_{8+}$ aromatics formation increases when pressure is increased [32], which is the opposite of the behavior observed in Figure 7d,f, respectively. However, it is important to highlight that the reactivity of dehydrogenation reactions increases with an increase in the carbon number of naphthenes [36]. The larger the hydrocarbon chain of the non-aromatic compounds of the naphtha feedstock, the larger the carbon number of the naphthene produced, so that the higher reactivity towards $C_{7}$ and $C_{8+}$ aromatics. 
Additionally, we also analyzed the effect of the $\mathrm{H}_{2} / \mathrm{HC}$ ratio on the distribution of aromatics (Figure 8). We found that the low R-value favors the production of the $A_{6}, A_{7}$, and $\mathrm{A}_{8+}$ aromatics at the equilibrium conditions as shown in Figure $8 \mathrm{a}, \mathrm{c}, \mathrm{e}$, respectively.
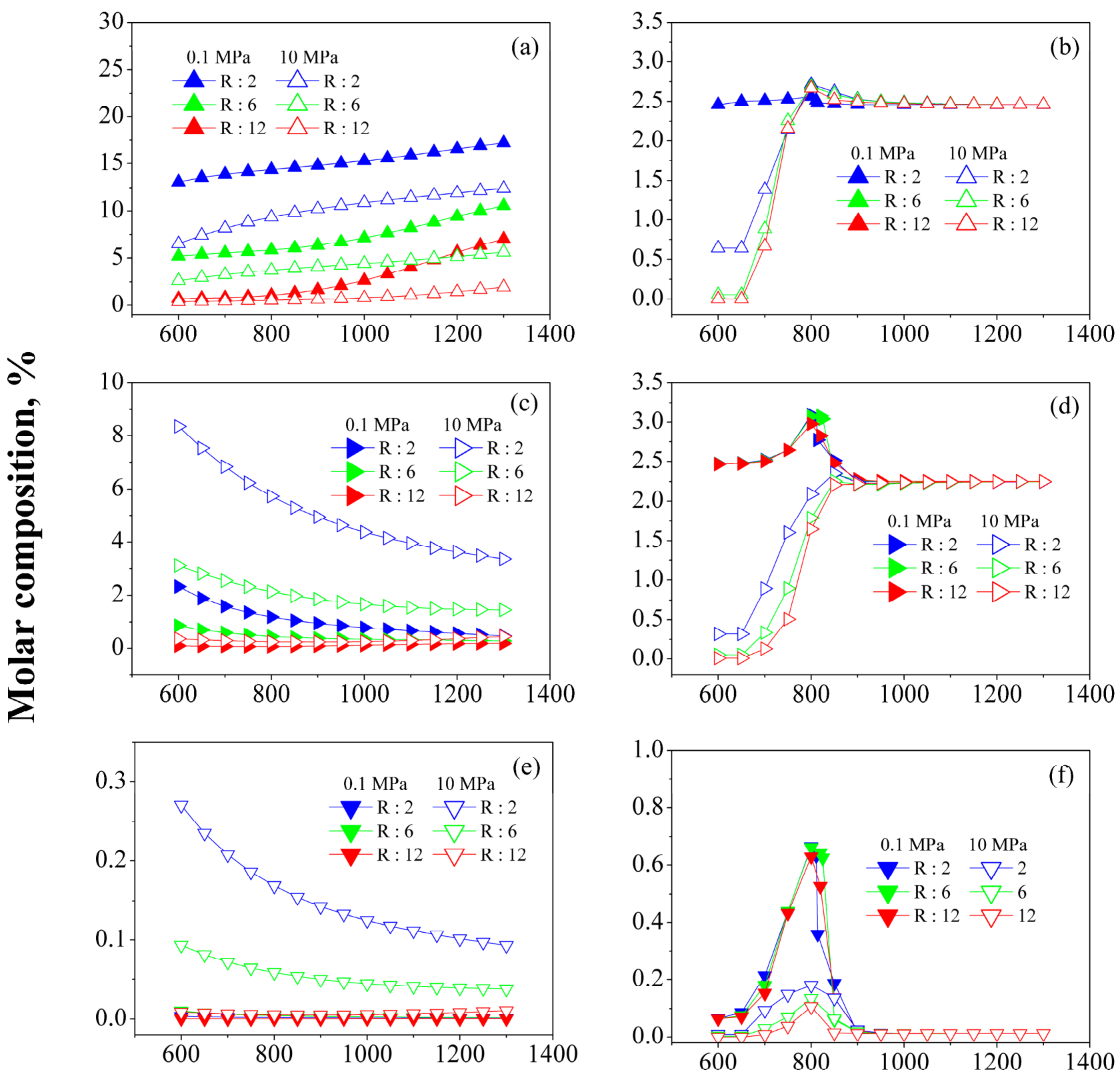

\section{Temperature, $\mathrm{K}$}

Figure 8. Effect of $\mathrm{H}_{2} / \mathrm{HC}$ ratio on aromatics distribution: (a,c,e) Equilibrium. (b,d,f) Catalytic. $(\boldsymbol{\Delta} / \Delta) \mathrm{C}_{6}$ Aromatics, $(\nabla / \nabla) \mathrm{C}_{7}$ Aromatics, $(\nabla / \nabla) \mathrm{C}_{8+}$ Aromatics.

Otherwise, we noticed in Figure $8 \mathrm{~b}$, d, f that the $\mathrm{H}_{2} / \mathrm{HC}$ ratio does not significantly impact the $\mathrm{C}_{6}-\mathrm{C}_{8+}$ aromatic production in the catalytic process, neither at high nor at low pressure. 


\subsection{Research Octane Number}

If the composition of fuel is known, the Research Octane Number (RON) may be estimated in the following form [24]:

$$
R O N=\sum v_{N P_{i}}(R O N)_{N P_{i}}+\sum v_{I P_{i}}(R O N)_{I P_{i}}+\sum v_{O_{i}}(R O N)_{O_{i}}+\sum v_{N_{i}}(R O N)_{N_{i}}+\sum v_{A_{i}}(R O N)_{A_{i}}
$$

The Research Octane Number for individual hydrocarbons was calculated as follow:

$$
\begin{gathered}
\text { RON }=a+b T+c T^{2}+c T^{3}+e T^{4} \\
T=\frac{T_{b}-273.15}{100}
\end{gathered}
$$

The coefficients $a-e$ are given in Table 10 .

Table 10. Coefficients for RON estimation [24].

\begin{tabular}{cccccc}
\hline Hydrocarbons & $\boldsymbol{a}$ & $\boldsymbol{b}$ & $\boldsymbol{c}$ & $\boldsymbol{d}$ & $\boldsymbol{e}$ \\
\hline n-Paraffins & 92.809 & -70.97 & -53 & 20 & 10 \\
Isoparaffins & & & & & \\
2-Methyl-pentanes & 95.927 & -157.53 & 561 & -600 & 200 \\
3-Methyl-pentanes & 92.069 & 57.63 & -65 & 0 & 0 \\
2, Dimethyl-pentanes & 109.38 & -38.83 & -26 & 0 & 0 \\
2, Dimethyl-pentanes & 97.652 & -20.8 & 58 & -200 & 100 \\
Naphthenes & -77.536 & 471.59 & -418 & 100 & 0 \\
Aromatics & 145.668 & -54.336 & 16.276 & 0 & 0 \\
\hline
\end{tabular}

Figure 9 shows the value of the octane number obtained with molar composition obtained at both equilibrium and catalytic conditions. It is observed that an increase in temperature induces an increase in the octane number; however, an increase in pressure results in a decrease in this property (Figure $9 \mathrm{a}, \mathrm{b}$ ). The impact of the $\mathrm{H}_{2} / \mathrm{HC}$ ratio on the $\mathrm{RON}$ at equilibrium is minimal. Increasing the R-value from 1 to 12 only increases the octane number by approximately 0.5 units (Figure 9c).

We can see in Figure 9c,d that there is a maximum increase in the octane number at temperatures close to $800 \mathrm{~K}$ for the different pressures and $\mathrm{H}_{2} / \mathrm{HC}$ ratios that were analyzed. This behavior is linked to the hydrocracking reactions inasmuch as they are favored at temperatures higher than $800 \mathrm{~K}$. Consequently, the fraction of aromatic compounds is diminished, and so is that of the $\mathrm{RON}$ value.

According to Figure 9, it is convenient to operate at low pressure. Nevertheless, it has been reported that decreasing the total pressure increases the coke formation over $\mathrm{Pt} / \mathrm{Al}_{2} \mathrm{O}_{3}$ catalysts. The increase in operating pressure contributes to less coke deposition on the metal function and higher stability, which is similar to adding Re or Ir to Pt to the catalyst [20]. When analyzing the effect of the $\mathrm{H}_{2} / \mathrm{HC}$ ratio on the RON value, we observed that it has no significant impact, but it has been found in previous literature reports that $\mathrm{H}_{2} / \mathrm{HC}$ ratios lower than 3.6 decreases aromatic production and increase carbon deposition [37].

It is essential to highlight that the catalytic naphtha reforming process is accompanied by side reactions that lead to carbonaceous deposits on both catalyst support and metallic sites, causing catalyst deactivation. Coke significantly alters the catalyst activity, selectivity, and lifetime [38].

Decreasing the $\mathrm{H}_{2} / \mathrm{HC}$ ratio at constant pressure produces more coke deposition on the support [20]. Carbon deposition decreased with increasing pressure [20]; nevertheless, it has been reported that coke deposits predominantly on the support at high pressures and can only be burned off at high temperatures, while the coke deposited under low pressure is more easily removed by regeneration [38]. Increasing the reaction temperature usually causes an increase in aromatics and reformate yields but also an increase in coke amount [20]. 

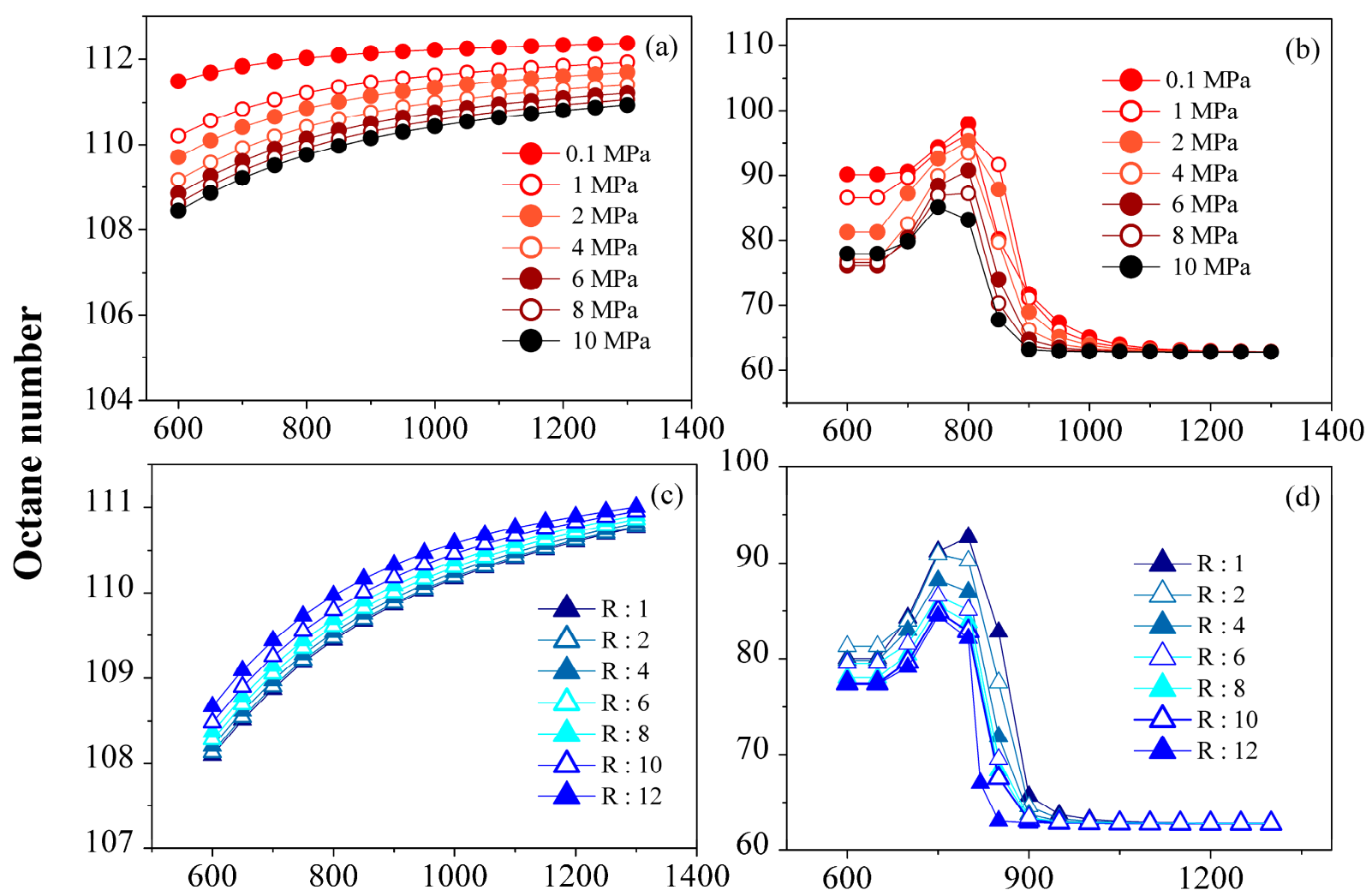

Temperature, $\mathbf{K}$

Figure 9. Effect of operating conditions on the Research Octane Number. Effect of pressure: (a) Equilibrium, (b) Catalytic. Effect of $\mathrm{H}_{2} / \mathrm{H}$ ratio (10 MPa): (c) Equilibrium, (d) Catalytic.

High severity accelerates coke formation and produces a decrease in aromatics and reformate yields [28], resulting in a decrease in the research octane. The decrease in the research octane number observed in Figure 9b,d at temperatures higher than $800 \mathrm{~K}$ agrees with the catalyst deactivation, which is incorporated in the reaction rate expressions for the catalytic reforming process (Tables 5-8) through the catalyst deactivation function given in Equation (15). It is recommended to operate below $823 \mathrm{~K}$, since an irreversible deactivation of the catalyst occurs beyond this temperature due to sintering and loss of surface area and mechanical resistance [37].

\section{Conclusions}

The effect of temperature, pressure, and $\mathrm{H}_{2} / \mathrm{HC}$ ratio on the products obtained from the naphtha reforming process was studied at equilibrium conditions and in the presence of $\mathrm{Pt} / \mathrm{Al}_{2} \mathrm{O}_{3}$ catalyst. In both cases, it is observed that an increase in temperature increases the production of aromatics. In contrast, an increase in pressure and $\mathrm{H}_{2} / \mathrm{HC}$ ratio decreases aromatics production. This is directly related to the Research Octane Number since this parameter highly depends on the aromatic content in the reformate.

It is important to highlight that the dehydrogenation of naphthenes towards aromatics production is completely favored under equilibrium conditions. However, during catalytic reforming, the aromatization reaction competes with the hydrocracking of paraffins and aromatics, significantly reducing the production of high-octane number compounds.

According to equilibrium calculations, the highest value of the RON expected was 108 . From the results of the simulation of the catalytic reforming, the highest RON value was 98 , at $800 \mathrm{~K}$. This gap in the RON value justifies the effort for the research for new catalysts 
and to evaluate alternative process configurations to reduce the severity of the process to obtain reformed gasoline with RON values greater than 98 .

Author Contributions: Conceptualization, J.M. and M.A.Z.-H.; methodology, J.M. and M.A.Z.-H.; software, J.M. and M.A.Z.-H.; validation, J.M. and R.S.R.-M.; formal analysis, J.M. and R.S.R.-M.; investigation, J.M.; resources, J.M. and M.A.Z.-H.; data curation, J.M. and R.S.R.-M.; writing—original draft preparation, J.M. and M.A.Z.-H.; writing-review and editing, J.M., M.A.Z.-H. and R.S.R.-M.; visualization, R.S.R.-M.; supervision, R.S.R.-M. All authors have read and agreed to the published version of the manuscript.

Funding: This research received no external funding.

Institutional Review Board Statement: Not applicable.

Informed Consent Statement: Not applicable.

Acknowledgments: The support provided by the UAM-Iztapalapa and Conacyt for this study is gratefully acknowledged by the authors.

Conflicts of Interest: The authors declare no conflict of interest.

\section{Nomenclature}

$a_{i j} \quad$ Number of gram atoms of element $\mathrm{j}$ in a mole of species $i$

$\mathrm{A}_{c} \quad$ Cross section of flow in reactor

$\triangle A \quad$ Sum of A coefficients in Table 3, according to reaction stoichiometry

$A_{i j} \quad$ Matrix of $a_{j i}$ 's

$\Delta B \quad$ Sum of B coefficients in Table 3, according to reaction stoichiometry

$B_{i} \quad$ B value of the i-th component of the mixture

$\Delta C \quad$ Sum of $C$ coefficients in Table 3, according to reaction stoichiometry

$\Delta C_{P} \quad$ Standard heat-capacity change of reaction

DH Dehydrogenation of naphthenes

DHC Dehydrocyclization of paraffins

$\mathrm{d}_{p} \quad$ Diameter of catalyst particle

$\Delta D \quad$ Sum of D coefficients in Table 3, according to reaction stoichiometry

$E_{a} \quad$ Activation energy

$\mathrm{E}_{d} \quad$ Deactivation energy

$\Delta E \quad$ Sum of E coefficients in Table 3, according to reaction stoichiometry

$\mathrm{F}_{i} \quad$ Molar flow

G Light gases in Figure 1

Superficial mass flux, $\mathrm{kg} / \mathrm{s} \cdot \mathrm{m}^{2}$ in Equation (7)

$\Delta G \quad$ Standard Gibbs-energy change of reaction at temperature $T$

$\Delta G_{0} \quad$ Standard Gibbs-energy change of reaction at reference temperature $T_{0}$

Standard Gibbs-energy change of formation of species $i$

$\Delta H_{0}$

Standard heat of reaction at reference temperature $T_{0}(298 \mathrm{~K})$

HDCrack Hydrocracking

i Carbon number: 6, 7, and 8+

ip Iso-paraffins

ISO Isomerization of paraffins

$K \quad$ Total number of atomic elements

$K_{i} \quad$ Equilibrium constant

$\mathrm{k}_{d} \quad$ Deactivation constant

$k_{D H} \quad$ Preexponential factor for the dehydrogenation reactions

$k_{D H C} \quad$ Preexponential factor for the dehydrocyclization reactions

$k_{D H C r a c k} \quad$ Preexponential factor for the hydrocracking reactions

$k_{I} \quad$ Preexponential factor for the isomeration reactions

$\mathrm{m} \quad$ Deactivation order

np Normal paraffins

$N \quad$ Total number of species in the reaction mixture.

Naphthenes in Figure 1 


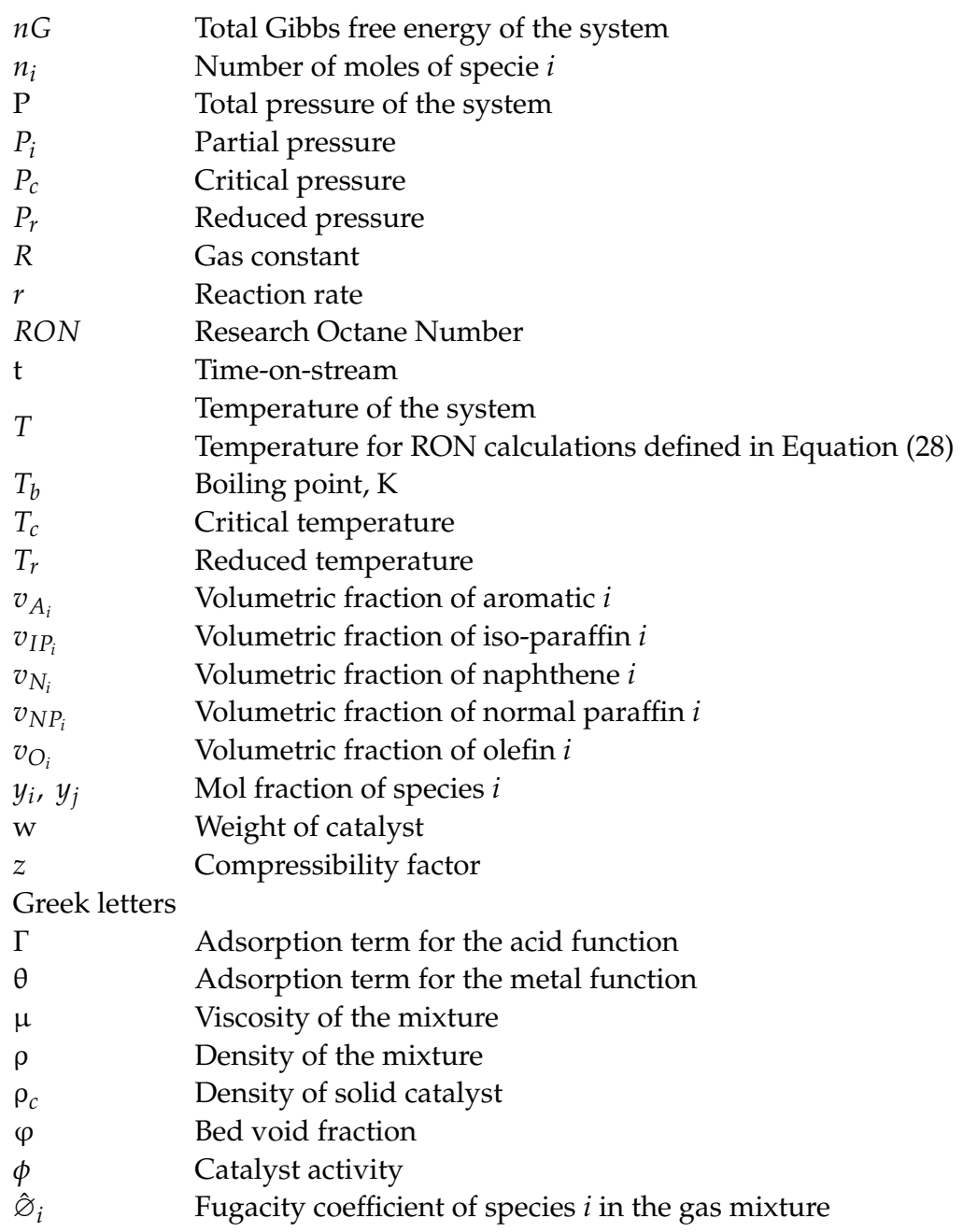

\section{References}

1. Maadah, G. Calculated Chemical Reaction Equilibrium for The Claus Process; Oklahoma State University: Stillwater, OK, USA, 1978.

2. White, W.B.; Johnson, S.M.; Dantzig, G.B. Chemical Equilibrium in Complex Mixtures. J. Chem. Phys. 1958, 28, 751-755. [CrossRef]

3. Tsanas, C. Simultaneous Chemical and Phase Equilibrium Calculations with Non-Stoichiometric Method. Ph.D. Thesis, Technical University of Denmark, Lyngby, Denmark, 2018.

4. Gao, J.; Wang, Y.; Ping, Y.; Hu, D.; Xu, G.; Gu, F.; Su, F. A thermodynamic analysis of methanation reactions of carbon oxides for the production of synthetic natural gas. RSC Adv. 2012, 2, 2358-2368. [CrossRef]

5. Lwin, Y. Chemical Equilibrium by Gibbs Energy Minimization on Spreadsheets. Int. J. Eng. Educ. 2000, 16, 335-339.

6. Bonilla-Petriciolet, A.; Rangaiah, G.P.; Segovia-Hernández, J.G. Constrained and unconstrained Gibbs free energy minimization in reactive systems using genetic algorithm and differential evolution with tabu list. Fluid Phase Equilibria 2011, 300, 120-134. [CrossRef]

7. Teh, Y.; Rangaiah, G. A Study of Equation-Solving and Gibbs Free Energy Minimization Methods for Phase Equilibrium Calculations. Chem. Eng. Res. Des. 2002, 80, 745-759. [CrossRef]

8. Seider, W.D.; Widagdo, S. Multiphase equilibria of reactive systems. Fluid Phase Equilibria 1996, 123, 283-303. [CrossRef]

9. Koukkari, P.; Pajarre, R. Calculation of constrained equilibria by Gibbs energy minimization. Calphad 2006, 30, 18-26. [CrossRef]

10. Lwin, Y.; Ramli, W.; Daud, W.; Mohamad, A.B.; Yaakob, Z. Hydrogen production from steam methanol reforming: Thermodynamic analysis. Int. J. Hydrogen Energy 2000, 25, 47-53. [CrossRef]

11. Adhikari, S.; Fernando, S.; Haryanto, A. A Comparative Thermodynamic and Experimental Analysis on Hydrogen Production by Steam Reforming of Glycerin. Energy Fuels 2007, 21, 2306-2310. [CrossRef]

12. Rossi, C.; Alonso, C.; Antunes, O.; Guirardello, R.; Cardozo-Filho, L. Thermodynamic analysis of steam reforming of ethanol and glycerine for hydrogen production. Int. J. Hydrogen Energy 2009, 34, 323-332. [CrossRef]

13. Wai, C.M.; Hutchison, S.G. Free energy minimization calculation of complex chemical equilibria: Reduction of silicon dioxide with carbon at high temperature. J. Chem. Educ. 1989, 66. [CrossRef]

14. Figueira, C.; Soares, R.; Lobato, F.; Steffen, V. A Comparative Study of Gibbs Free Energy Minimization in a Real System Using Heuristic Methods. Comput. Aided Chem. Eng. 2009, 27, 1059-1064. [CrossRef] 
15. Ancheyta-Juárez, J.; Villafuerte-Macías, E. Experimental validation of a kinetic model for naphtha reforming. Stud. Surf. Sci. Catal. 2001, 615-618. [CrossRef]

16. Zagoruiko, A.N.; Belyi, A.S.; Smolikov, M.D. Thermodynamically Consistent Kinetic Model for the Naphtha Reforming Process. Ind. Eng. Chem. Res. 2021, 60, 6627-6638. [CrossRef]

17. $\mathrm{Hu}, \mathrm{Y}$;; $\mathrm{Su}, \mathrm{H}$.; $\mathrm{Chu}$, J. Modeling, simulation and optimization of commercial naphtha catalytic reforming process. In Proceedings of the 42nd IEEE International Conference on Decision and Control (IEEE Cat. No.03CH37475), Maui, HI, USA, 9-12 December 2003. [CrossRef]

18. Rodríguez, M.A.; Ancheyta, J. Detailed description of kinetic and reactor modeling for naphtha catalytic reforming. Fuel 2011, 90, 3492-3508. [CrossRef]

19. Ross, J.R. Catalysis in the Production of Energy Carriers from Oil; Elsevier: Amsterdam, The Netherlands, 2018; pp. 233-249. [CrossRef]

20. Rahimpour, M.R.; Jafari, M.; Iranshahi, D. Progress in catalytic naphtha reforming process: A review. Appl. Energy 2013, 109, 79-93. [CrossRef]

21. Joseph, M.; Smith, C.H.; van Ness, M.; Abbott, M.; Swihart, T. Introduction to Chemical Engineering Thermodynamics, 8th ed.; McGraw-Hill: Singapore, 2018.

22. Walas, S.M. Phase Equilibra in Chemical Engineering; Butterworth-Heinemann: Oxford, UK, 1985.

23. Chemical \& Physical Properties by Cheméo. Available online: https:/ / www.chemeo.com/ (accessed on 14 July 2021).

24. Riazi, M.R. Characterization and Properties of Petroleum Fractions, 1st ed.; ASTM: Philadelphia, PA, USA, 2005.

25. Turaga, U.T.; Ramanathan, R. Catalytic Naphtha Reforming: Revisiting Its Importance in the Modern Refinery. J. Sci. Ind. Res. 2003, 62, 963-978.

26. Arani, H.M.; Shirvani, M.; Safdarian, K.; Dorostkar, E. Lumping procedure for a kinetic model of catalytic naphtha reforming. Braz. J. Chem. Eng. 2009, 26, 723-732. [CrossRef]

27. Taskar, U.M. Modeling and Optimization of a Catalytic Naphtha Reformer; Texas Tech University: Lubbock, TX, USA, 1996.

28. Prins, R.; Schuit, G.C.A. (Eds.) Chemistry and Chemical Engineering of Catalytic Processes; (NATO ASI series. Series E: Applied sciences; Vol. 39); Sijthoff \& Noordhoff: Noordwijkerhout, The Netherland, 1980.

29. Rigutto, M.S.; van Veen, R.; Huve, L. Zeolites in Hydrocarbon Processing. Stud. Surf. Sci. Catal. 2007, 168, 855-913, XXVI. [CrossRef]

30. Ramírez, S.; Martínez, J.; Ancheyta, J. Kinetics of thermal hydrocracking of heavy oils under moderate hydroprocessing reaction conditions. Fuel 2013, 110, 83-88. [CrossRef]

31. Castañeda, L.; Muñoz, J.; Ancheyta, J. Comparison of approaches to determine hydrogen consumption during catalytic hydrotreating of oil fractions. Fuel 2011, 90, 3593-3601. [CrossRef]

32. Elsayed, H.A.; Menoufy, M.F.; Shaban, S.A.; Ahmed, H.S.; Heakal, B.H. Optimization of the reaction parameters of heavy naphtha reforming process using Pt- $\mathrm{Re} / \mathrm{Al}_{2} \mathrm{O}_{3}$ catalyst system. Egypt. J. Pet. 2017, 26, 885-893. [CrossRef]

33. Fink, J. Processes. In Guide to the Practical Use of Chemicals In Refineries and Pipelines; Gulf Professional Publishing: Houston, TX, USA, 2016; pp. 185-223. [CrossRef]

34. Kjell, M.; Gunn, H.H.; Anne, H.; Ingunn, T.; Knut, G.; Anders, H. Effect of Reaction Pressure on Octane Number and Reformate and Hydrogen Yields in Catalytic Reforming. Ind. Eng. Chem. Res. 1996, 35, 99-105.

35. Yusuf, A.Z.; John, Y.M.; Aderemi, B.O.; Patel, R.; Mujtaba, I.M. Effect of hydrogen partial pressure on catalytic reforming process of naphtha. Comput. Chem. Eng. 2020, 143, 107090. [CrossRef]

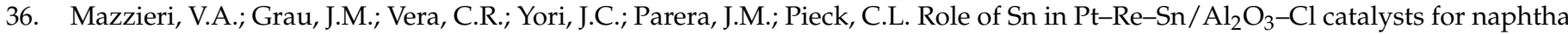
reforming. Catal. Today 2005, 107-108, 643-650. [CrossRef]

37. Bishara, A.; Stanislaus, A.; Hussain, S.S. Effect of feed composition and operating conditions on catalyst deactivation and on product yield and quality during naphtha catalytic reforming. Appl. Catal. 1984, 13, 113-125. [CrossRef]

38. George, J.A.; Aitani, A.M. Catalytic Naphtha Reforming, 2nd ed.; Marcel Dekker, Inc.: New York, NY, USA, 2004 